\title{
Bioética y el Derecho de Acceso a los Medicamentos
}

\author{
BIOETHICS AND THE RIGHT OF ACCESS TO MEDICINES
}

Salvador Darío Bergel ${ }^{(*)}$

\section{EXTRACTO}

Las discusiones en el campo del bioethics vuelven, generalmente, alrededor de los temas específicos tales como manipulación genética, transplantes de órganos, entre otros. Este artículo demuenstra otra dimensión del bioethics, la que está relacionada con las cuestiones de la salud pública y, especialmente, con el acceso a los medicamentos à las poblaciones de los países menos ricos. Esto significa que el bioethics está ligado necesariamente a las actuais circunstancias políticas e económicas. Los questionamientos éticos nascidos de las análisis del papel de los estados y de los organismos internacionales para garantizar el acceso a los medicamentos han estado cambiando, sin embargo muy lentamente, ciertos dogmas puramente de la comercialización y han estado estableciendo un equilibrio más racional y más humano entre los derechos à la propiedad industrial y los intereses de la salud pública. Ésa es la razón que el "declaración de Doha" significa un avance substancial en la lucha de los países subdesarrollados para ofrecer medicamentos accesibles a sus poblaciones

\section{Palabras clave}

Acceso a los Medicamentos; Bioética; Ética; Política de Medicamentos.

\section{ABSTRACT}

Debates in the field of bioethics, in general, turn around of specific subjects such as genetic manipulation, transplants of organs, among others.

(*)Director de la Catedra de Bioética da Unesco de la Universidad de Buenos Aires. E-mail: <s.bergel@ezabog.com.ar>. Recebido em 25.8.06. Aprovado em 13.9.06. 
This article shows another dimension of bioethics, the one related to the questions of public health and, specially, to the access to medicines to the populations of the less rich countries. This means that bioethics is necessarily associated to the current politician and economic circumstances. Ethical questions that have came to light from the analysis of the role of the States and of the international organisms in order to guarantee the access to medicines has been changing, even so very slowly, certain purely marketing dogmas and establishing a more rational and human balance between the rights of the industrial property and the interests of the public health. That is the reason that "Doha's Declaration" means a substantial advance in the fight of the underdeveloped countries to offer accessible medicines to its populations.

\section{Key words}

Access to Drugs; Bioethics; Ethics; Medicines Politics.

\section{RESUMO}

Os debates no campo da bioética, em geral, giram em torno de temas bastante específicos como manipulação genética, transplantes de órgãos, entre outros. Este artigo traz à tona uma outra dimensão da bioética relacionada às questões de saúde pública e, em especial, ao acesso aos medicamentos por parte das populações dos países menos desenvolvidos. Dentro deste arcabouço, a bioética está necessariamente ligada às cirscunstâncias político-econômicas atuais. Os questionamentos éticos provocados a partir da análise do papel do Estado e de organismos internacionais na garantia do acesso aos medicamentos vêm transformando, embora muito lentamente, certos dogmas puramente mercadológicos e estabelecendo um equilíbrio mais racional e mais humano entre os direitos da propriedade industrial e os interesses da saúde pública. Nessa linha, nasceu a "Declaração de Doha", que implicou em um avanço substancial na luta dos países subdesenvolvidos para oferecer medicamentos acessíveis aos seus povos.

\section{Palavras-chave}

Acesso a Medicamentos; Bioética; Ética; Política de Medicamentos.

\section{UNA NUEVA VISIÓN DE LA BIOÉTICA}

El abordaje ético del acceso a los medicamentos involucra aspectos políticos, económicos y jurídicos que - en un primer examen - podría considerarse que desorbita el campo de la indagación. 
Para entender la postura que aquí asumimos, es necesario referirnos a la reciente evolución de la bioética

Berlinger, uno de los bioeticistas más destacados del presente, señala en uno de sus lúcidos ensayos que "el tema de la salud raramente está presente en el debate bioético; le es comúnmente negado el título de nobleza como objeto de ética y en el mejor de los casos le es atribuido sólo el valor (que para algunos es considerado filosóficamente irrelevante e intelectualmente plebeyo) de cuestión social"(1).

Es que los debates bioéticos transcurren de común en torno a problemas "más específicos y más actuales", tales como la fecundación médica asistida, los dilemas de la nueva genética, los transplantes de órganos, los límites de los cuidados intensivos, la investigación en embriones, etc. Sin desconocer la importancia que asumen estos temas no podemos dejar de advertir que los problemas vinculados con la salud colectiva junto a los factores que la condicionan debieran estar en el centro de la reflexión bioética, para que esta disciplina de corta historia no se transforme en algo desvinculado de la realidad que envuelve a millones de hombres.

Cabe recordar que la bioética nació y se cultivó en los países del Norte con una marcada tendencia que privilegió los problemas y dilemas nacidos de la investigación médica en un momento de hondas transformaciones originadas en el espectacular salto de las ciencias biológicas y médicas, a partir de la segunda mitad del siglo pasado. En su devenir cabe observar que el reciente desarrollo de los estudios bioéticos no es sólo patrimonio de los países del Norte sino que, en un plano más universal, la disciplina fue ampliando considerablemente sus dominios al incorporar temas que parecieran pertenecer al campo de lo económico social, pero que en definitiva guardan estrecha relación con la vida de los hombres. Desde hace tiempo que con creciente énfasis se han incorporado a su campo de reflexión temas tales como la pobreza, el hambre, la exclusión social, la mal nutrición, el acceso al agua potable, etc.

De esto no podemos colegir que la bioética esté invadiendo campos reservados a la política ${ }^{(2)}$. Simplemente es obligado reconocer que las políticas económicas y sociales se encuentran indisolublemente unidas a su esfera de interés. En esta línea compartimos con R. Zatti que "el escenario moderno configura una nueva imagen de la bioética: no sólo una "rama del saber" sino una multiforme experiencia de formación del consenso en torno

(1) Berlinger, G. Ética de la salud. Buenos Aires: Lugar Edit., 1996. p. 17.

(2) Garrafa esclarece el campo de la controversia: la bioética incursiona en la política para incluir las cuestiones sociales en su agenda. Eso no es biopolítico. Es la bioética interviniendo en una dimensión más amplia: la política. (GARRAFA, V. Inclusão social no contexto político da bioética. Revista Brasileira de Bioética, v. 1, n. 2, p. 122, 2005). 
a problemas, elecciones morales, opciones políticas o jurídicas que apuntan a la relación entre ciencia y los valores del hombre"(3).

Hablar de una enfermedad, ignorando los factores ligados a su origen y desarrollo o considerar al sujeto como algo disociado de las circunstancias económicas y sociales que condicionan su vida importa, al menos, caer en un reduccionismo alejado de la realidad vital.

Desde los años 70 del siglo pasado - que se considera como fecha de nacimiento de esta disciplina - hasta el presente se han visualizado una serie de problemas y dilemas que apuntan a un campo ensanchado. EI avance y reinstalación de enfermedades vinculadas con la exclusión social, fruto del abandono del estado de bienestar y de la generalización de políticas económicas neoconservadoras que agudizan los problemas generados por la pobreza y el hambre y que restringen considerablemente las posibilidades de acceso a los servicios de salud ha llevado a los cultores de la bioética a asumir posiciones más radicalizadas encaminadas a darle un perfil acorde con la realidad social en la que opera. Esta tendencia ha tenido un notable desarrollo en Latinoamérica.

Aquí surgieron posiciones que apuntan a una "bioética de intervención" y a una "bioética de protección", con una notable orientación política y social que apunta a un mayor nivel de compromiso con los problemas sociales que aquejan a la región y que son comunes a otras regiones del tercer mundo ${ }^{(4)}$.

La reciente Declaración Universal Sobre Bioética y Derechos Humanos de la UNESCO del 12 de octubre de 2005 da un claro respaldo a estas posturas en cuanto toca temas como el hambre, la exclusión social, la mal nutrición, la salud pública y el acceso a la salud y a los medicamentos (en especial el Artículo 14, titulado "Responsabilidad Social en Salud"). Partiendo

(3) ZATTI, R. Verso un diritto per la bioética. In:MAZZONI, C. M. (a cura di). Una norma giuridica per la bioética. Bologna: II Mulino, 1988. p. 63.

(4) La bioética de intervención - a juicio de Garrafa - identifica e incorpora la dimensión social de la persona como una totalidad somática en la cual están articuladas las dimensiones físicas y psíquicas que se manifiestan de manera integrada en las relaciones sociales y en las relaciones con el medio ambiente (op. cit., p. 127). La bioética de protección, según Schramm, fue pensada inicialmente para dar cuenta de los conflictos morales que se dan en el campo de la salud y de la calidad de vida de los individuos y poblaciones que, por una razón u otra, no estaban (y no están) "cubiertas" en sus derechos ciudadanos; es decir, pensada para proteger a aquellos que, por sus condiciones objetivas de vida y/o salud, son susceptibles o fragilizadas al punto de no poder realizar sus potencialidades y proyectos de vida normalmente legítimos; pues las políticas públicas de salud no las garantizan. Es una ética aplicada mínima o de "primer nivel" (como escribe Atalán), algo como una condición necesaria para decirse que estamos en el campo de la ética y para que los susceptibles o fragilizados tengan alguna posibilidad de vivir dignamente y realizar sus proyectos razonables de vida compartida con los demás (SCHRAMM, F. R. Bioética sin universalidad. Justificación de una bioética latinoamericana y caribeña de protección. In: Garrafa, V.; Kottow, M.; Saada, A. (Coords.). Estatuto epistemológico de la bioética. México: UNAM, 2005. p. 165). 
de esta nueva realidad vamos a examinar el tema del acceso a los medicamentos con un enfoque que, sin desconocer que nos movemos dentro del campo de la bioética, contemple las políticas públicas que se reclaman en esta materia.

\section{EL DERECHO A LA VIDA, A LA SALUD Y AL ACCESO A LOS SERVICIOS DE SALUD Y MEDICAMENTOS}

Antes de entrar a la consideración particular de cada uno de los derechos enunciados en el título, estimo que vale la pena explicar las razones que justifican traer a este debate la teoría de los derechos humanos.

Tal como lo enseña Hottois( ${ }^{(5)}$, la problemática llamada hoy "bioética" ha llegado a mezclarse desde hace 50 años a la problemática de los derechos humanos, agregando que "los derechos humanos constituyen un sólido muro de contención contra toda voluntad - realista o no - de inscribir biológicamente (genética y hereditariamente) en la humanidad diferencias jerarquizantes que desemboquen de modo abierto o no a distinguir individuos, unos con menos valor y otros con mayor valor. La igualdad importa igualmente una preocupación de equidad que hace que los derechos humanos vayan en el sentido de un acceso igual para todas las fuentes y los medios de la biomedicina". Y en sintonía con esta posición Maldonado agrega que "es preciso decir que los derechos humanos no son una preocupación especialmente jurídica, ni siquiera en el sentido más generoso de la palabra, ya que por el contrario son una preocupación eminentemente ética y sólo porque es ética es adicionalmente un asunto político, jurídico y económico"(6).

En el análisis del tema que nos ocupa existen tres derechos humanos que pese a guardar una íntima y directa relación presentan características propias.

El primero de los derechos referidos, el derecho a la vida, es el más abarcativo, en tanto no resulta posible hablar de salud ni de acceso a los servicios de salud o a los medicamentos si no se contempla la propia vida.

La Declaración Universal de los Derechos Humanos, reconoce en su artículo 3 que "Todo individuo tiene derecho a la vida, a la libertad y a la seguridad de su persona".

En contra de la tradicional caracterización del derecho a la vida como un derecho para cuya satisfacción basta con que el Estado no atente contra

(5) Hottois, G. Bioética y derechos humanos. In:ESCOBAR TRIANA, J. Y et al. (Orgs.). Bioética y derechos humanos. Bogota: Ediciones del Bosque, 1998. p. 151. (Colección Bios y Ethos).

(6) MALDONADO, C. E. Necesidad de esencia y comunidad de problemas de la bioética y los derechos humanos. In: ESCOBAR TRIANA, J. Y et al. (Orgs.). op. cit., p. 95. 
la vida de sus habitantes, existe un amplio conjunto de obligaciones que requieren de la actividad positiva del Estado. En este sentido el emplazamiento del derecho a la vida entre los derechos civiles y políticos no restringe el carácter de las obligaciones referidas.

Tal como lo recuerda Seúbe, tanto la doctrina como la práctica jurisprudencial han abandonado la misión restrictiva del derecho a la vida que limita las obligaciones de los estados a no atentar contra la vida de las personas y han empezado a señalar las obligaciones positivas que derivan del mismo. Entre otros factores en esta evolución ha influido tanto la evidencia que no puede disociarse el derecho a la vida de la muerte de miles de personas al año por inanición o falta de acceso a los medicamentos, como la puesta en práctica de la noción de interdependencia e indivisibilidad de los derechos humanos ${ }^{(7)}$.

Estrechamente vinculado al derecho a la vida se encuentra el derecho a la salud, receptado en el artículo 25 de la Declaración Universal de los Derechos Humanos, en estos términos: "toda persona tiene derecho a un nivel adecuado que le asegure, así como a su familia, la salud y el bienestar y en especial la alimentación, el vestido, la asistencia médica y los servicios sociales necesarios".

Dos años antes de proclamada la Declaración, en el preámbulo de los estatutos de la OMS podía leerse que "el beneficio de gozar de elevados niveles de salud es uno de los derechos fundamentales del ser humano, sin distinción de razas, de religión, de credo político, condición social o económica".

El derecho a la salud, al igual que otros económicos y sociales, viene precedido por un cierto hálito de ineficacia; estigma que tiene por origen las dudas acerca de su judicialidad y que se manifiesta - al decir de Seúbe - en problemas concretos de claridad conceptual y solapamiento con otros derechos. A esta concepción no es ajena una visión fragmentada de los derechos humanos que coloca a los derechos económicos y sociales en un plano inferior a los civiles y políticos ${ }^{(8)}$.

Uno de los argumentos que se repiten para sostener la pretendida distinción de los derechos civiles y políticos con respecto a los económicos, sociales y culturales, radica en la supuesta característica de obligaciones negativas del primer género de derecho, mientras que la segunda implicarían el nacimiento de obligaciones positivas que en la mayoría de los casos deben solventarse con recursos del erario público(9).

(7) SEÚBE HERNÁNDEZ, X. El Derecho al acceso a los medicamentos esenciales y el comercio internacional de productos farmacéuticos. 2004. (Tesis) — Universidad Pompeu Fabra, Barcelona, 2004. Inédito. (8) Id. Ibid.

(9) ABRAMOVICH, V.; COUTIS, C. Hacia la exigibilidad de los derechos económicos, sociales y culturales. In:ABREGÚ, M.; COUTIS, C. Aplicación de los Tratados sobre derechos humanos por jueces locales. Buenos Aires: Editorial del Puerto, 1997. p. 2. 
Conforme a una concepción que cuenta con muchos adeptos, la fuerza vinculante, la exigibilidad o bien la propia juridicidad de derechos económicos, sociales y culturales resulta dudosa ya que la satisfacción de estos depende de la disponibilidad de recursos por parte del Estado. Este denunciado "condicionante económico" relativizaría la universalidad de los derechos de marras condenándolos a ser de "segunda categoría".

Sin embargo - agregan Abramovich y Courtis - si observamos la evolución de las funciones y roles del Estado en la gestación y promoción de los derechos civiles y políticos podremos advertir que tales actividades no se circunscriben a la mera función pasiva de no interferir en el goce de los mismos. Desde esta perspectiva las diferencias entre derechos civiles y políticos por un lado, y derechos económicos, sociales y culturales, por otro, lejos de ser sustanciales, apuntan a un mayor o menor grado de intervención ${ }^{(10)}$.

Más allá de reconocer que las facetas más visibles de los derechos económicos, sociales y culturales son obligaciones de hacer, lo que condujo a denominarlos "derechos-protección", no cabe reconocer diferencias relevantes.

Contreras Peláez haciéndose cargo de la imposibilidad de distinción tajante entre ambos tipos de derechos, sostuvo que para los derechos sociales, la prestación estatal representa verdaderamente la sustancia, el núcleo, el contenido esencial del derecho. Pero es del caso anotar que muchos derechos fundamentales comprendidos en el catálogo de civiles y políticos han sido reinterpretados en clave social, de modo que las distancias absolutamente pierden sentido en estos casos ${ }^{(11)}$.

Si bien la función positiva de prestación en los derechos económicos y sociales es relevante, no podemos negar que el desarrollo de políticas de estado que no requieren de prestaciones traducidas en erogaciones económicas contribuyen decisivamente al goce de los mismos. Sirva de ejemplo la regulación sobre medicamentos genéricos que abarata sensiblemente el costo de los mismos, sin afectar su calidad y efectividad.

Reconocida la categoría de derechos económicos y sociales que ostentan, cabe recordar que el artículo 2.1. del Pacto Internacional de Derechos Económicos, Sociales y Culturales establece el compromiso de adoptar medidas hasta el máximo de los recursos que se disponga para lograr progresivamente por todos los medios apropiados, inclusive en particular la adopción de medidas legislativas, la plena efectividad de los derechos, lo que conlleva a la progresividad, vinculada estrechamente con la prohibición de regresividad. 
Berlinger relaciona el derecho a la salud con el derecho a la asistencia sanitaria. Se debe reconocer - a su juicio - que conforman dos aspectos estrechamente unidos entre sí, pero distintos en su origen por su construcción ética y por su forma de actuar ${ }^{(12)}$. El acceso a los servicios de salud es un derecho al que hay que reconocerle una configuración propia, derivada del genérico derecho a la salud.

Cuando la salud se resquebraja - por diversos motivos que no viene al caso mencionar - llega la hora de la verdad a fin de ver concretado en los hechos el derecho reconocido. La asistencia sanitaria oportuna, apropiada a las circunstancias del caso, de calidad, hace al respeto del principio ético de equidad en la esfera sanitaria.

Este derecho debe ser de alcance universal. No cabe sostener la existencia de diversos grados de atención conforme a las particularidades del caso, o a la ubicación del sujeto en el plano social, lo cual no empece a destacar las relaciones intrincadas entre mercado y salud, que muchas veces obstaculizan llevar a feliz término estas premisas.

Por último cabe referirnos al tema que concita nuestra atención: el derecho de acceso a los medicamentos. No es posible hablar del derecho a la vida o a la salud sin involucrar el acceso a los medicamentos, acceso que no se agota con el simple suministro a quien lo necesite.

Tal acceso debe posibilitar el cumplimiento de la función que se le reconoce en la órbita sanitaria, para lo cual deben converger una serie de requisitos:

- que el acceso sea oportuno, es decir que el suministro llegue a tiempo para poder ejercer su función terapéutica;

- que lo sea de la calidad y en la cantidad debida. Esto impone el cumplimiento de funciones indelegables por parte del Estado en lo concerniente al control de calidad y paralelamente en garantizar la provisión durante todo el tiempo que sea necesario en relación con la causa que lo genera(13).

- que quien acceda se encuentre en condiciones de sufragar su costo sin ver afectadas significativamente sus condiciones de vida. Esto es importante sobre todo si se toma en consideración que las innovaciones en el campo de la industria farmacéutica son de un costo elevado que en general no guardan relación con los ingresos de los pacientes;

(12) BERLINGER, G. op. cit., p. 62.

(13) Menos de un tercio de los países pobres poseen autoridades regulatorias y en muchos de estos países una muestra del 10 al $30 \%$ de los medicamentos no atiende a condiciones mínimas de calidad. La ausencia de buenas prácticas de fabricación y fiscalización adecuadas frecuentemente lleva a la elaboración de productos tóxicos y a veces letales. La expansión del comercio de medicamentos tiene en sí misma desafíos para asegurar patrones globales de calidad (TAPAJÓS, A. M. Patentes e asesso a medicamentos: estudio bioético de la Declaração de Doha. 2005. (Tesis). Brasilia 2005. Inédito). 
- que quien acceda a su suministro tenga un adecuado nivel de información. La información es relevante para la utilización racional de los medicamentos, a fin de evitar el consumo de drogas que no cumplen una función terapéutica para el caso, o lo que es más grave aún, puedan provocar consecuencias perjudiciales para el consumidor;

- que el medicamento sea efectivo para el uso al que se lo destina. Ana María Tapajós señala que el acceso a los medicamentos se inserta en un cuadro más amplio que envuelve la promoción de la salud, la prevención y la recuperación. De esta forma es lo mismo no tener acceso a los servicios como tener acceso a servicios sin efectividad ${ }^{(14)}$.

El suministro de medicamentos inadecuados o en dosis superiores a las necesarias puede conducir a la creación de resistencia a los agentes patógenos, lo que a su vez compromete el futuro de la salud del usuario.

Un medicamento - enseña Rossi- es el resultado de unir al producto una información y un contexto. En un contexto dado no sólo cuentan las regulaciones específicas, sino la forma de organización social, el "orden económico global" y la organización de los servicios de salud. Estamos hablando de política(15).

El acceso a los medicamentos necesariamente debe ser analizado y discutido en el ámbito general de las políticas sanitarias ya que de otra forma caemos en la simplificación - inaceptable por cierto - de dejar al mercado como regulador y árbitro de la salud colectiva, olvidando el compromiso primigenio del Estado para con la sociedad.

A juicio de Germán Velázquez el Estado debe asumir la responsabilidad complementaria de un conjunto de funciones básicas en el sector farmacéutico: elaboración de políticas de financiamiento, regulación en materia de medicamentos, establecimiento de normas profesionales, fomento del uso racional de los medicamentos, etc. Estas funciones constituyen el mínimo de lo que debe hacerse cargo el Estado(16).

Debe quedar en claro que no basta con la contribución económica del Estado a través de vías diversas: compras masivas, subsidios, provisión gratuita, etc. Es imprescindible que tal contribución - válida por cierto - se vea complementada con otras acciones de no menor importancia.

Los mercados de medicamentos requieren una corriente de información completa y precisa entre los compradores y los vendedores. El desequilibrio

(14) Id. Ibid.

(15) ROSSI, F. Enfermedades de alto impacto social, enfermedades olvidadas, medicamentos de alto costo y ARV. In:BERMÚDEZ, J.; OLIVEIRA, M. A.; ESHER, A. Acceso a medicaméntos: derecho fundamental: papel del Estado. Rio de Janeiro: Fiocruz, 2004. p. 193.

(16) VELÁSQUEZ, Germán. El papel del Estado en el financiamiento de los medicamentos. In:BERMÚDEZ, J.; OLIVEIRA, M. A.; ESHER, A. op. cit., p. 32. 
de la información entre los productores de medicamentos y los proveedores de los servicios de salud y entre estos y los pacientes es una de las principales causas de falla en el mercado de productos farmacéuticos ${ }^{(17)}$.

Las diferencias entre el mercado de los servicios de salud y los medicamentos y otros mercados (desequilibrio de información, escasa competencia, externalidad y objetivos distintos de lucro), justifica ampliamente la intervención del Estado a fin de restablecer el necesario equilibrio entre las partes.

De lo hasta aquí reseñado surge que el derecho humano al acceso a los medicamentos importa la puesta en marcha de mecanismos complejos con la intervención de diversos actores, entre los que prima el Estado como garante de la salud colectiva.

\section{EL PAPEL DEL ESTADO}

Hemos señalado que la función del Estado en torno al acceso a los medicamentos no puede limitarse a una posición pasiva y que lejos de agotarse con la entrega material del medicamento a quien lo necesite, importa una serie de obligaciones que en definitiva convergen a una adecuada protección de la salud pública, traducido en la formulación de políticas sanitarias ${ }^{(18)}$.

Es importante asegurar la calidad de los medicamentos disponiendo de los controles adecuados, a la par de velar por una utilización racional de los mismos.

En 1985 durante la Conferencia Mundial sobre uso racional de los medicamentos, celebrada en Nairobi, se estableció que existe uso racional cuando los pacientes reciben medicamentos apropiados a sus necesidades clínicas, en dosis adecuadas a las particularidades individuales, por período de tiempo adecuado y con bajo costo para ellos y su comunidad. Es natural que el uso racional esté relacionado con las políticas de información y educación.

Pero tal vez el tema más relevante para este análisis sea el del costo del medicamento, condicionante que a la postre se convierte en la principal barrera para el acceso.

El Estado debe intervenir mediante la implementación de políticas adecuadas en el suministro, control de calidad, racionalidad en el uso y fijación de precios.

(17) Id. Ibid., p. 25.

(18) Los objetivos de la salud pública y los intereses comerciales de las empresas a veces coinciden y a veces divergen. No son idénticos. Cuando entran en colisión, deberían ser siempre capaces de optar por la salud pública como una razón legítima de limitar o condicionar los intereses y derechos comerciales (ZAFAR, M., en: WHO/DAP/98.9). 
Sin desconocer los límites fijados por el sistema de economía de mercado es posible desarrollar políticas que conduzcan a la fijación de precios razonables y eviten la especulación que a la postre se traduzca en una privación del acceso a grandes sectores de la población.

Tomando en cuenta el carácter de bien público que le asignamos al medicamento, tales políticas regulatorias no sólo importan una facultad legítima de los estados sino que se convierten en un deber inexcusable, ya que la salud colectiva no puede quedar librada a la suerte de los vaivenes de una industria que no reconoce límites a sus apetitos de lucro.

Se ha demostrado que la reducción de los precios está en directa relación con el número de pacientes que accede a los medicamentos, los que en un supuesto contrario se verían privados de las terapias para combatir la dolencia que padecen.

Un estudio realizado en Uganda estimó que reduciendo el precio de una terapia triple de ARV de 6.000 a 600 dólares al año se incrementa la demanda de tratamientos de 1.000 a 50.000 pacientes. De igual forma un estudio econométrico mundial ha calculado que si se eliminara las patentes a una muestra representativa de países en desarrollo se obtendría un aumento del acceso a las terapias de ARV de un $30 \%{ }^{(19)}$.

Diversas son las políticas que puede ensayar el Estado en esta dirección. Una de las más efectivas es la que apunta a la facilitación de la competencia a través de los medicamentos genéricos.

El medicamento genérico es un producto farmacéutico que se considera intercambiable con el producto innovador y se suele fabricar sin licencia de la empresa innovadora y comercializar una vez expirada la patente u otros derechos de exclusividad ${ }^{(20)}$.

Con la caducidad de las patentes por el mero transcurso del tiempo de validez, los medicamentos experimentan una continua erosión de relativa inelasticidad precio-demanda, resultante de la discriminación notable de diferenciación de los productos, una vez que los medicamentos genéricos lanzados son iguales a los productos invocados, desviando la concurrencia para el precio.

Las políticas de genéricos, ensayadas en numerosos países, han posibilitado una sensible disminución de precios una vez que vence la patente.

Otra forma de intervención consiste en la facilitación de importaciones paralelas desde mercados en los que habiendo ingresado legalmente el medicamento, es vendido a un precio menor que el comercializado en el

(19) INFORME de la Comisión sobre Derechos de Propiedad Intelectual del Reino Unido. In:TEMAS de Derecho Industrial y de la Competencia, n. 7. Buenos Aires: Ciudad Argentina, 2005. p. 122.

(20) WHO/DAP/98.9. 
país. Asimismo el otorgamiento de licencias obligatorias constituye otra de las armas a las cuales puede acceder el Estado para combatir una especulación abusiva.

El propio Acuerdo TRIP's autoriza el otorgamiento de licencias obligatorias para restablecer la competencia en caso de abuso de posición dominante de las empresas farmacéuticas, traducido en la fijación de precios exorbitantes. Las severas condiciones a las que somete el acuerdo el otorgamiento de tales licencias, constituyen un serio obstáculo a su utilización. La flexibilización de estos recaudos - tal como lo advirtió la Declaración de Doha - constituye un objetivo importante a lograr por los países menos desarrollados.

El informe de la Comisión sobre Derechos de Propiedad Industrial del Reino Unido aconsejó que los países deben adoptar una variedad de políticas para mejorar el acceso a los medicamentos, señalando que se deben armonizar otras políticas macroeconómicas y el sistema de propiedad intelectual con los objetivos de políticas de salud(21).

\section{LOS "MEDICAMENTOS HUERFANOS" Y DE ALTO COSTO}

Un problema importante que toca el campo de la justicia global es el que presentan los denominados "medicamentos huérfanos", problema que pone al desnudo la referida doble función de los medicamentos como bienes sociales y como mercancía.

El término fue utilizado por primera vez en 1968 para referirse a las drogas potencialmente útiles que no están disponibles en el mercado por no ser lucrativas y se lo amplió posteriormente para referirse a la inexistencia de medicamentos para combatir nuevas enfermedades propias o preponderantes de los países pobres ${ }^{(22)}$.

No se trata de barreras existentes para el acceso a los medicamentos disponibles en el mercado, sino de la falta de producción o de distribución de medicamentos para combatir las enfermedades de la pobreza que - a juicio del mercado - no ofrecen una rentabilidad aceptable ${ }^{(23)}$.

(21) INFORME de la Comisión sobre Derechos de Propiedad Intelectual del Reino Unido, cit., p. 128.

(22) SILVA, C. dos Santos; ZEPEDA BERMÚDEZ, J. Medicamentos esepcionais ou de alto custo no Brasil. In:BERMÚDEZ, J.; OLIVEIRA, M. A.; ESHER, A. op. cit., p. 203.

(23) Cabe destacar la forma en que afrontan los países el tema de los denominados medicamentos huérfanos. En los Estados Unidos desde 1982 se estableció un sistema de promoción para medicamentos huérfanos (Orphan Drug Act/Food and Drug Administration (ODAFDA), iniciativa que fue seguida por otros países como Japón, Australia y los de la Unión Europea.

Por razones obvias los países subdesarrollados se vieron precisados a prescindir de esta acción. En los casos indicados los medicamentos huérfanos recibieron como incentivo créditos federales, subsidios del Congreso, un período de exclusividad de comercialización y exención de tasas. 
Esto nos acerca a las llamadas "enfermedades olvidadas", patologías que no son otras que las enfermedades de los pobres de los países pobres - en especial los ubicados en el Trópico - y que están estrechamente relacionadas con las míseras condiciones de vida de grandes masas de población, que no llegan a constituir un mercado puesto que aún, partiendo de la existencia de una demanda, los interesados no poseen medios para acceder a los mismos ${ }^{(24)}$.

Las enfermedades olvidadas de los países desarrollados y subdesarrollados configuran una serie de dolencias tales como la malaria, el dengue, el mal de chagas, la leismañosis y algunas respiratorias agudas, que a la postre constituyen la mayor causa de muerte dentro de sectores carenciados.

Si es verdad que históricamente las patentes han estimulado el descubrimiento de nuevos medicamentos, cabe destacar que la industria farmacéutica está sometida a los imperativos del mercado. De allí que los nuevos medicamentos puestos en el mercado no son, precisamente, los más apropiados a los fines terapéuticos de la mayoría de la población mundial(25).

El análisis de este tema no sólo pone en evidencia la falta de interés en la eventual producción y comercialización de las drogas por parte de la industria farmacéutica multinacional - conducta de por sí reprochable - sino que hay que agregar un ingrediente complementario: la falta de interés de los centros de investigación de los países desarrollados para ocuparse de las enfermedades de la pobreza ${ }^{(26)}$.

Desde 1975 a 2004, se comercializaron mil quinientos cincuenta y seis nuevos fármacos y sólo veinte de ellos (el 1,3\%) tratan enfermedades tropicales, a lo que cabe agregar que varios de los medicamentos existentes no están adaptados a la situación particular de los países ${ }^{(27)}$. En este sentido, Iván llich señaló que "la mayoría de los establecimientos de investigación se reservan para investigadores programados para interpretar al mundo en términos de ganancia y de poder y la mayoría de los fines de la investigación se determina por móviles de poder y eficiencia. Esta es una reflexión que debiera incorporarse a los debates sobre propiedad intelectual en el sector farmacéutico".

(24) ROSSI, F. op. cit., p. 195.

(25) VELÁSQUEZ, E. Médicaments essencials et mondialisation. Revue International de Droit economique, v. 1, 2000. p. 38.

(26) Cabe señalar que recientemente a iniciativa de Médicos sin Fronteras se creó un grupo de trabajo de medicamentos para dolencias olvidadas que presentó algunas recomendaciones para salir del impase: establecer una agenda global de investigaciones bien definidas y motivada por necesidades, empeño en la búsqueda de soluciones por parte de los gobiernos que deben cumplir con sus responsabilidades, aumento de la formación de investigadores de enfermedades olvidadas y exploración de un nuevo emprendimiento sin fines de lucro para atender la carencia en I y D. de las dolencias más olvidadas.

(27) PECUL, V. Los gobiernos deben responsabilizarse por tratar las enfermedades olvidadas. El País, Madrid, 18 abr. 2006. 
Habría que tomar muy en cuenta lo arriba anotado para salirle al paso a los promotores de la industria farmacéutica multinacional cuando pretenden fundar sus exorbitantes ganancias en la necesidad de contar con fondos "para seguir investigando". Correspondería interrogarse acerca de los criterios de selección de tales investigaciones ${ }^{(28)}$.

Siendo que, como lo hemos caracterizado, los medicamentos constituyen un bien social y que en su suministro están comprometidas políticas esenciales e insoslayables del Estado no podemos de hablar de acceso a los medicamentos sin comprender a los "medicamentos huérfanos".

El acceso a los medicamentos no puede limitarse a lo que provee el mercado farmacéutico, ya que la salud pública no puede subordinarse a los menguados fines económicos que persiguen las empresas farmacéuticas.

Si no existe en la industria interés en producir y comercializar determinados fármacos, tal tarea prioritariamente debe ser asumida por el Estado, por sí, o a través de organismos que le están ligados.

Igualmente, dentro de los deberes que debe asumir el Estado en cuanto a la protección y promoción de la salud pública cabe incorporar la realización de investigaciones orientadas a la erradicación de enfermedades que no cuentan con terapias adecuadas.

En esta línea la 56 asamblea Mundial de la Salud, advirtiendo que la investigación y desarrollo en el sector farmacéutico debe responder a las necesidades de salud pública y no sólo a las posibilidades de obtener beneficios comerciales, instó a los Estados miembros a que procuren crear condiciones favorables a la investigación y desarrollo de nuevos medicamentos contra enfermedades que afectan a los países en desarrollo.

Los países subdesarrollados víctimas de muchas de ellas deben adoptar una posición activa, creando planes de investigación con otros países que concurran a la búsqueda de medicamentos eficaces para tales fines.

\section{LOS CRITERIOS DE JUSTICIA, EQUIDAD Y SOLIDARIDAD EN EL ACCESO A LOS MEDICAMENTOS}

La atención de la salud comprende la asistencia médica, la cual a su vez engloba etapas en cuyo desarrollo aparece necesariamente el tema del acceso a los medicamentos.

(28) Uno de los principales argumentos que se aducen en pro de las patentes farmacéuticas es que son necesarias para la I. y D. Sin embargo en los países en desarrollo el $75 \%$ de la población mundial consume sólo un $14 \%$ de la oferta mundial de medicamentos. Un $15 \%$ de la población de los países industrializados consume el $86 \%$. Las políticas de libre cambio y los acuerdos comerciales no están enfrentando el evidente fallo del mercado en cuanto a desarrollar y comercializar medicamentos accesibles para las enfermedades que están más extendidas en las regiones pobres como la tuberculosis, el paludismo y el VIH / SIDA (Mirza Zafer, en: WHO/DAP/98.9). 
Las disparidades sociales que presenta la desigualdad de ingresos y de oportunidades en la población hacen que se desdibuje el ideal de justicia como meta a alcanzar en el acceso a los medicamentos, en tanto el trato igualitario entre quienes exhiben puntos de partida diferentes conspira para el logro de la finalidad propuesta. De allí que resulte más ajustado a la realidad manejarse con el concepto de equidad que apunta a que los iguales sean tratados de igual forma y que los desiguales sean tratados en forma desigual. De esta manera la equidad se convierte en un principio comparativo, en un criterio sobre la situación que la persona o grupo de personas ocupan en relación con los demás, favoreciendo una especie de discriminación positiva ${ }^{(29)}$.

La aplicación de criterios de justicia rígida, indiferenciada, que se aparte de la observancia de los matices concretos que presenta cada situación en particular, sólo puede conducir a consagrar en los hechos verdaderas injusticias.

Si lo que se pretende es llegar a todos con un sistema de atención efectiva y eficiente, no queda otro camino que considerar las diferencias que se observan en el seno de la sociedad. La premisa - se ha señalado es que la equidad en salud no puede ser un concepto apolítico, acultural, tecnocrático, limitado al campo de la asistencia sanitaria o al de la salud pública. La mejor forma de considerar la equidad en el campo de la salud no es como un objetivo social en sí mismo y aislado, sino como algo inherente a la búsqueda de una forma amplia de justicia social(30).

Cuando la OMS lanza el plan de medicamentos esenciales con acceso irrestricto a los ciudadanos del mundo; cuando se apunta a flexibilizar el régimen de patentes para posibilitar el acceso de los pueblos aquejados por la pandemia de SIDA a las drogas retrovirales; cuando se impulsa ofrecer medicamentos genéricos a precios accesibles; se está recurriendo a criterios de equidad para hacer efectiva la justicia social tanto a nivel interno como a nivel global.

Considerar a la salud como el resultado del azar biológico escindido de la multiplicidad de factores socioeconómicos que la condicionan y que la determinan en grado significativo, sólo conduce a una visión superficial, reduccionista, no comprometida, que aparta del análisis los datos más significativos y enriquecedores. Partiendo de las naturales diferencias biológicas entre los individuos - que no pueden ser evitadas por la acción humanaqueda un amplio campo a los problemas "evitables" con el esfuerzo mancomunado de hombres y de pueblos; un espacio reservado a la solidaridad.

El principio de equidad apela al principio de solidaridad como condición de su efectivización: la igualdad de derechos entre todos los hombres

(29) PETER, F.; EVANS, T. Dimensiones de la equidad en salud: In: AA. Desafío de la falta de equidad en la salud. Washington: OPS, 2000. p. 290.

(30) /d. Ibid., p. 28. 
sólo puede ser restablecida de hecho, si también todos los hombres redistribuyen todos sus bienes entre sí. Y la salud no puede constituir una excepción a esos criterios generales ${ }^{(31)}$. En esta línea Rossi destaca que el principio de distribuir por los costos (principio de solidaridad) de acuerdo a los ingresos de cada uno, de los eventos de la enfermedad (principio de equidad), asumiendo en cierto modo que los problemas de salud son de "todos" y los pagamos entre "todos" de acuerdo con la capacidad de cada uno, constituye un avance enorme ${ }^{(32)}$.

En 1975 la Asamblea Mundial de la Salud, ante la crisis que afligía a los países en desarrollo, provocada por el alto costo de los medicamentos que imposibilitaba su acceso, adoptó una resolución en la que por vez primera se introducen los conceptos de "política farmacéutica nacional" y "medicamentos esenciales" en el vocabulario de la salud pública internacional.

Acorde con este mandato, en 1981 la OMS creó el programa de acción sobre medicamentos esenciales; entendiendo por tales a aquellos que satisfacen las necesidades del cuidado de salud de la mayoría de la población y que deben por tanto estar disponibles en todo momento, en cantidades adecuadas y en presentaciones apropiadas, a un precio que la comunidad pueda pagar ${ }^{(33)}$. Las listas de medicamentos esenciales las elabora la OMS anualmente atendiendo a su impacto para la salud pública, la evidencia sobre su eficacia o inocuidad y el precio accesible para las personas y para la comunidad. Se confeccionan en base a numerosos programas de salud desarrollados con el objeto de reducir tanto la morbo-mortalidad en los países en desarrollo, cuanto los gastos de medicamentos que compromete parte importante de sus ingresos. En 2002 por primera vez el listado incorporó doce ARV para el tratamiento del SIDA.

Esta campaña ha tenido un desarrollo positivo traducido en un considerable aumento de la población con acceso a estos listados de medicamentos.

El garantizar el acceso a los medicamentos esenciales es considerado hoy como una de las responsabilidades indelegables del Estado y constituye un tema incluido en la agenda de los diferentes países y organismos internacionales. El numeral 17 de las Metas de las Naciones Unidas para el Milenio establece especialmente la necesidad de "propiciar el acceso a los medicamentos esenciales en los países en desarrollo".

No obstante todas las acciones desarrolladas en esta dirección, la OMS señala que aun hoy un tercio de la población mundial continúa sin un acceso regular a estos medicamentos. Tomando en cuenta que en las poblaciones pobres el $60 \%$ de las muertes son producidas por infecciones parasi-

(31) PATRÃO NEVES, M. do Céu. Alocação de recursos em saúde: considerações éticas. Bioética, Brasilia, v. 7, n. 2, p. 163, 1999.

(32) ROSSI, F. op. cit., p. 194.

(33) WHO/DAP/98.9. 
tarias, tuberculosis y malaria, para todas las cuales el acceso oportuno a los medicamentos es generalmente decisiva para prolongar la vida y reducir el sufrimiento, podemos advertir lo que significa que un tercio de la población mundial carezca aún de acceso a los medicamentos esenciales.

En África 320 millones de personas sólo tienen acceso a menos del $50 \%$ de la lista de medicamentos esenciales; lo cual a esta altura del siglo constituye una verdadera afrenta a la dignidad de los seres humanos, que nos debería avergonzar.

La Dra. Gro Harlem Brundtland, ex Directora de la OMS, recordó que nunca ha tenido el mundo tantas armas terapéuticas para enfermedades que afligen a la humanidad, pero al mismo tiempo existe una necesidad vital de medicamentos y vacunas nuevas. Esto es cierto para las enfermedades emergentes, pero también lo es para la seria amenaza que supone la resistencia creciente a medicamentos empleados contra enfermedades mortíferas tan comunes como el paludismo, la meningitis bacteriana y la neumonía ${ }^{(34)}$.

Pese a la encomiable labor de la OMS en el plano internacional, estamos lejos de haber concretado la propuesta "Salud para todos en el año 2000". Los países más pobres, casi abandonados de la mano de Dios, diezmados por deudas externas imposibles de pagar, víctimas de prácticas comerciales que ostensiblemente afectan sus ingresos (subsidios, barreras aduaneras, etc.), son los que están más alejados de poder ofrecer a sus habitantes la provisión universal de medicamentos esenciales.

El aumento del arsenal terapéutico no se tradujo en un correlativo aumento del acceso a los medicamentos, en tanto quienes menos ingresos tienen o simplemente carecen de ellos, no pueden sufragar el precio y la contribución estatal en muchos casos es insuficiente o simplemente inexistente.

Todo ello conduce a la triste comprobación que el slogan "salud para todos" se traduce en muchos casos en "salud para quienes cuentan con los medios para el acceso".

Esta lamentable comprobación debe servir para redoblar los esfuerzos tendientes a sortear las barreras que obstaculizan el acceso universal a los medicamentos, ya que así podría efectivizarse en los hechos el tantas veces pregonado derecho a la salud.

\section{EL PAPEL DE LOS DERECHOS DE PROPIEDAD INDUSTRIAL: DOHA Y MÁS ALLÁ DE DOHA}

El obstáculo más importante para el acceso a los medicamentos lo sigue constituyendo el sistema de propiedad intelectual, que si bien ha expe-

(34) BRUNDTLAND, G. H., en OMS: Globalización, acceso a los medicamentos (WHO/DAP/98.9). 
rimentado una cierta flexibilización después de Doha - tal como lo examinamos más abajo - mantiene serias restricciones traducidas en la imposición de altos precios y en el aprovechamiento de la estructura monopólica de los mercados, junto a las barreras que impone a la producción local en los países subdesarrollados.

A todo ello cabe adicionar que muchos paises en desarrollo se han visto forzados a aceptar niveles más altos de protección de la propiedad industrial que los establecidos en los Acuerdos ADPIC, tales como los que impusieron los Estados Unidos en los "Acuerdos de libre comercio" a Singapur, Jordania, Chile, países centroamericanos, Colombia, Peru, etc. Esta nueva vuelta de tuerca acentúa aún más la situación de desventaja en que se encuentran estos países, ya que incidirá necesariamente en el acceso a los medicamentos a los sectores carenciados.

Decíamos que el acceso a los medicamentos encuentra una valla - a veces difícil de sortear - en el régimen de patentes, en tanto que éstas confieren monopolios temporales que no sólo influyen en el precio, sino que - paralelamente - retardan la introducción de la competencia. Esto movió a numerosos países en su hora a excluir de la protección patentaria a los medicamentos por considerarlos bienes públicos; privilegiando de esta forma el resguardo de la salud de sus habitantes.

Al cerrarse la ronda Uruguay del GATT (hoy OMC), uno de los efectos centrales que produjo fue la virtual globalización del sistema de patentes pese a que en teoría se sigue sosteniendo que se trata de derechos territoriales. Un capítulo central lo constituye el Acuerdo sobre los aspectos de los derechos de propiedad intelectual relacionados con el comercio (ADPIC) que estableció estándares mínimos de protección patentaria, de observancia obligatoria para los países que integran el sistema multilateral de comercio allí creado, so pena de sufrir sanciones comerciales en caso de infracción.

Siendo que la pertenencia a la OMC constituye una imperiosa necesidad de los Estados, cabe sostener que lo acordado en ADPIC en los hechos, es de acatamiento general y obligatorio. Tal como lo entiende Remiche, la filosofía del Acuerdo consiste en la adopción de medidas idénticas para el mundo entero y resulta de una visión del mundo que lo concibe como un gran mercado. Esta visión no resiste el análisis ante la evidencia revelada de un mundo diferenciado en el que ciertos intereses legítimos pueden ser contradictorios $^{(35)}$.

Particularmente en el caso de las patentes se estableció que los Estados no podrán hacer distinciones fundadas en una rama de la tecnología,

(35) REMICHE, B. Les brévets farmaceutiques entre l'interêt privé et public: un equilibre imposible? Révue Internationale de Droit Économique, v. 1, p. 197, 2000. 
con lo cual los países que hasta entonces excluían a los medicamentos de la protección patentaria se vieron constreñidos en la necesidad de modificar sus legislaciones.

Conforme a ello, durante todo el período de vigencia de las patentes ahora armonizado en veinte años - el titular goza del derecho exclusivo de fabricar el producto, comercializarlo, licenciarlo, importarlo y exportarlo. Si a esto adicionamos la circunstancia ya conocida que la industria farmacéutica es monopólica, concentrada cada vez más en un puñado de multinacionales que poseen la mayoría de las innovaciones en este campo, tenemos como corolario natural que el acceso a los medicamentos protegidos por patentes - que constituye el segmento más utilizado en el tratamiento de dolencias humanas - depende en gran medida de decisiones empresarias (fijación de precios, regalías, concesión de licencias, importación, exportación, etc.), sólo orientadas por el incremento del lucro.

El mercado farmacéutico no puede ser descripto por el modelo de mercado clásico de competencia perfecta, habida cuenta de la existencia de una serie de factores tales como la asimetría en la información - los consumidores carecen de común de la información necesaria para valorar la eficacia y eficiencia del producto - la tendencia a la inelasticidad de la demanda o de los precios - tomando en consideración, entre otras cosas, el carácter esencial del bien, los aumentos de precio no se reflejan proporcionalmente en el consumo - la fidelidad a las marcas y las barreras de entrada a nuevos productos (tecnológicas, de escala y metodológicas). Estas circunstancias convergen en la reducción de posibilidades de sustitución del producto, ya sea por la falta de opciones en el mercado o por la no identificación de tales opciones por parte de los consumidores ${ }^{(36)}$.

Lo referido pone de manifiesto que en un caso concreto quien experimente la necesidad de un determinado producto farmacéutico queda prisionero del mercado y es sabido que la industria farmacéutica es una de las más rentables en función de los precios desmedidos que impone ${ }^{(37)}$.

Cuando se trata del suministro de drogas insustituibles para curar una dolencia o prolongar una vida podemos advertir en toda su dimensión lo perverso del sistema imperante.

Durante un tiempo los países menos desarrollados soportaron estoicamente los efectos nefastos del sistema impuesto en la OMC, sin hallar mayor

(36) REIS, A. L. de Almeida dos; BERMÚDEZ, J. Aspectos económicos: mercados farmacéuticos y precio de medicamentos. In: BERMÚDEZ, J.; OLIVEIRA, M. A.; ESHER, A. op. cit., p. 139.

(37) Las diferencias de costo entre el principio activo y la especialidad medicinal que lo contiene resulta muchas veces abismal, lo cual ha sido demostrado en numerosos estudios. Así, se ha verificado que de doce medicamentos indicados para una serie de enfermedades, los precios en los Estados Unidos eran de 4 a 56 veces el precio de los productos equivalentes en la India, estado que aún no protege a los productos farmacéuticos por patentes, utilizando el plazo de gracia establecido en el Acuerdo ADPIC. 
eco en la comunidad de naciones, hasta que la pandemia de SIDA obligó a los países más afectados a utilizar recursos heroicos.

Sudáfrica rompió el cerco injusto e inhumano impuesto por el orden internacional y su gobierno decidió privilegiar la vida y la salud de sus habitantes por encima de los intereses del mercado desconociendo de hecho el régimen creado por el Acuerdo ADPIC, lo que la expuso a una multiplicidad de demandas judiciales promovidas por las multinacionales farmacéuticas.

Lo que estaba en juego era la vida de más de cuatro millones de infectados, la necesidad de evitar sufrimientos evitables y al mismo tiempo de poner una barrera a la difusión del mal(38).

La reacción general que suscitó las demandas judiciales encabezadas por diversas ONG mostró al mundo la inequidad y falta de solidaridad de las actoras, las que - finalmente - debieron desistir de sus pretensiones ante la repulsa generalizada.

No obstante esta solución puntual, el problema que lo generó - la pretendida primacía de los intereses del mercado por sobre los de la salud colectiva - quedó en pie. En razón de ello, el grupo africano en el seno de la OMC instó a que se considerara al más alto nivel la relación entre salud pública y los Acuerdos ADPIC.

Ya en 1996 la Asamblea Mundial de la Salud (OMS) había examinado la relación entre la salud pública y los acuerdos ADPIC. Las resoluciones adoptadas en 2001 apuntaron a la necesidad de evaluar el impacto del Acuerdo ADPIC sobre el acceso, la capacidad de fabricación local y el desarrollo de nuevos medicamentos. Con posterioridad, a raíz del clima creado por los atentados a las torres gemelas surgió la denominada "crisis del carbunclo" generada por el temor a la diseminación del ántrax, por actos terroristas, lo que colocó a los Estados Unidos ante la eventualidad de tener que responder a una demanda generalizada de la única droga efectiva, cuya patente pertenece a una multinacional, la cual no se encontraba en condiciones de suministrarla ni en la cantidad ni en el tiempo requeridos.

El temor a un desenlace cruento - finalmente disipado - llamó a la reflexión sobre la necesidad de establecer un equilibrio más racional y humano entre los derechos de propiedad industrial que esgrimen las empresas y los intereses de la salud pública. Ya no se trataba de un reclamo de países del África Subsahariano, sino de un problema que se le podría haber presentado a la mayor potencia económica mundial.

(38) Para tener una idea aproximada de las exorbitantes ganancias de la industria farmacéutica, señalamos que entre julio de 2000 y abril de 2002 el costo anual de la combinación de terapia triple ARV de marca se redujo de más de US $\$ 10,000$ anuales por individuo a poco más de US\$700, para un grupo seleccionado de consumidores. Para ese entonces el precio genérico más bajo de esa combinación había descendido a US\$290. 
Bajo este clima se celebró el IV período de sesiones de la Conferencia Ministerial de la $\mathrm{OMC}$ que examinó la precitada relación y que como fruto de sus deliberaciones produjo el 14.11.01 la denominada "Declaración de Doha", que implicó un avance sustancial en la lucha de los países subdesarrollados por brindar medicamentos accesibles a sus pobladores.

La declaración comienza por marcar la gravedad de los problemas de salud pública que afligen a muchos países en desarrollo y a los menos adelantados, especialmente por la epidemia de VIH/SIDA, tuberculosis, paludismo; y al mismo tiempo reconoce que el acuerdo sobre los ADPIC no impide ni debería impedir que los miembros adopten medidas para proteger la salud pública afirmando, en ese sentido, que dicho acuerdo puede y debe ser interpretado y aplicado de una manera que apoye el derecho de los miembros de la OMC de proteger la salud pública y en particular de promover el acceso de medicamentos para todos.

Cabe señalar la relevancia que cobra esta Declaración que por primera vez un órgano clave del sistema económico internacional reconoce y privilegia los intereses de la salud pública, a los que coloca por encima de los derechos de propiedad industrial.

Paralelamente reconoce que el Acuerdo ADPIC contiene flexibilidades en su aplicación, tales como:

a) el deber de los miembros de conceder licencias obligatorias y la de determinar las bases sobre las cuales se concederán tales licencias;

b) el derecho a determinar lo que constituye una emergencia nacional u otra circunstancia de extrema urgencia, quedando entendido que las crisis de salud pública, incluidas las relacionadas con el VIH/SIDA, tuberculosis, paludismo y otras epidemias, pueden representar una emergencia nacional $u$ otras circunstancias de extrema urgencia.

La declaración ministerial, que puede ser considerada como una interpretación autorizada del Acuerdo, constituyó - sin dudas - una victoria de los países menos desarrollados al poner en un primer plano la defensa de los intereses vinculados con la salud colectiva por encima de los intereses particulares que pueden derivar de la observancia de los derechos de propiedad industrial y de los acuerdos vinculados a ellos.

Tal como lo destaca Correa, la Declaración de Doha no pretende enmendar el Acuerdo sobre los ADPIC de ninguna manera sustancial. La Declaración no incluye la totalidad de las áreas en las que existe flexibilidad en el Acuerdo sobre ADPIC, tales como las excepciones a los derechos de patentes, la protección de los datos personales para el registro de productos farmacéuticos; tampoco hace referencia a la libertad que deja a los Miembros para determinar los estándares de patentabilidad de forma de impedir el 
desarrollo de estrategias de patentamiento dirigidas a cumplir o a extender temporalmente la protección conferida en el área farmacéutica ${ }^{(39)}$.

Constituyó una fisura dentro de un sistema monolítico y perverso, que no ha sido desarticulado, pero que abre un destello de luz en los caminos de solidaridad y de equidad. Posteriormente un acuerdo complementario del 3.8.03 aclaró algunos aspectos de su ejecución; que permitió la concesión de licencias obligatorias con vista a la exportación para atención de demandas de los países que tienen poca o ninguna capacidad de producción, suspendiendo temporariamente las sanciones contempladas en el acuerdo.

Tal como se ha señalado, al separar a la salud pública y especialmente los productos farmacéuticos de los demás temas relacionados con el comercio, la Declaración de Doha reconoce que los medicamentos no son cualquier mercadería, debiendo ser diferenciados de las demás mercancías al proteger la salud pública ${ }^{(40)}$.

No obstante ello, su aplicación puede resultar difícil en razón de la complejidad y pesadez de los procedimientos que deben ponerse en acción para ejecutarlo.

Lo aconsejable es la reforma del Acuerdo ADPIC de forma tal que los países menos desarrollados queden al margen de las obligaciones allí establecidas con relación a los medicamentos. En la realidad de los hechos su participación en el mercado mundial de medicamentos es mínima y los problemas que deben afrontar para satisfacer las necesidades sanitarias de sus habitantes importan relevantes sacrificios. Igualmente deben orientarse los esfuerzos para que los países menos desarrollados puedan contar con tecnología propia, sin necesidad de tener que recurrir a terceros países para importar el medicamento. El propio texto del acuerdo original establecía que los países desarrollados ofrecerían a las empresas e instituciones de los países menos adelantados incentivos destinados a fomentar y propiciar la transferencia de tecnología con el fin de que estos puedan establecer una base tecnológica racional y viable. Lamentablemente no se ha cumplido con esto y la transferencia de tecnología prometida quedó en los papeles.

No es posible que el proceso de globalización se traduzca en exigencias desmedidas para estos países que no condicen con los beneficios que ellos acordaron a los industrializados. Aquí se impone la observancia de conductas solidarias por parte de los países desarrollados que permita a los países del tercer mundo superar los problemas creados por la crisis de salud que los envuelve. Tal como lo entiende la OMS, para hacer frente a los nuevos problemas de salud de repercusión internacional como la aparición

(39) WHO/EDM/PAR/2002.3.

(40) VELÁSQUEZ, Germán; CORREA, Carlos M.; BALASUBRAMANIAM, Thirkumarann. La OMS al frente de la lucha por el acceso a los medicamentos. In:BERMÚDEZ, J.; OLIVEIRA, M. A.; ESHER, A. op. cit., p. 104. 
del Síndrome Respiratorio Agudo Severo (SRAS), el acceso a nuevos medicamentos con posibles efectos terapéuticos, así como las innovaciones y los descubrimientos en materia de salud, deben estar a disposición de todos sin discriminación.

La lucha por el acceso universal a los medicamentos en condiciones razonables, que no importe agravar la situación económico-social de los países menos desarrollados ni infligir a las poblaciones carenciadas mayores sacrificios y padecimientos constituye no sólo una decisión política, sino que paralelamente debe comprometer los esfuerzos dirigidos al logro de una mayor solidaridad entre naciones y pueblos.

Refiriéndose a este problema, Adela Cortina señalaba "que millones de personas estén amenazadas de muerte en los países en desarrollo por SIDA, tuberculosis o malaria; que existan los fármacos adecuados para el tratamiento y que el derecho de patentes haga absolutamente imposible para esas gentes acceder a ello, es un crimen contra la humanidad. Y justamente contra la humanidad más inerme y por lo mismo la más vulnerable"(41).

Creo que ha llegado el momento en el cual la comunidad de naciones tome al toro por las astas e invierta los términos de la ecuación. En lugar de tomar como punto de partida la defensa de los derechos derivados de la propiedad industrial a favor de la industria farmacéutica, se torna imprescindible comenzar por analizar la situación en materia sanitaria de una parte considerable de los países menos desarrollados, en especial de África y Latinoamérica, y emprender una campaña solidaria para hacer realidad el sueño de "medicamentos para todos".

Si es necesario flexibilizar los Acuerdos de ADPIC, excluir a los países pobres de su régimen, prolongar los plazos de gracia para el patentamiento de fármacos, permitir importaciones paralelas, habrá que recurrir a ello. Igualmente los países desarrollados deberían contribuir a la solución de los problemas que plantean a los países subdesarrollados las dificultades económicas al acceso a los medicamentos mediante donaciones o condonaciones de deuda.

La humanidad constituye una gran familia a la cual nadie puede sustraerse. Los problemas de un país o de un continente tarde o temprano impactarán en los demás. La insensibilidad con la pandemia de SIDA o con la tuberculosis, o el paludismo, tarde o temprano va a revertir sobre los países desarrollados.

En lugar de elaborar presupuestos inconmensurables para la compra de armamentos destinados a la destrucción de poblaciones de enemigos imaginarios, debemos reclamarles una cuota de racionalidad y de solidaridad, ya que nada ni nadie habrá de apartar a la comunidad de naciones de un destino común.

(41) CORTINA, A. La arrogancia neoliberal. EI País, Madrid, 16 set. 2003. 


\section{REFERENCIAS}

ABRAMOVICH, V.; COUTIS, C. Hacia la exigibilidad de los derechos económicos, sociales y culturales. In: ABREGÚ, M.; COUTIS, C. Aplicación de los Tratados sobre derechos humanos por jueces locales. Buenos Aires: Editorial del Puerto, 1997.

BERLINGER, G. Ética de la salud. Buenos Aires: Lugar Edit., 1996.

BRUNDTLAND, G. H. In: OMS: Globalización, acceso a los medicamentos. (WHO/DAP/98.9).

CORTINA, A. La arrogancia neoliberal. El País, Madrid, 16 set. 2003.

GARRAFA, V. Inclusão social no contexto político da bioética. Revista Brasileira de Bioética, v. 1, n. 2, 2005.

HOTTOIS, G. Bioética y derechos humanos. In: Escobar Triana, J. Y et al. (Orgs.). Bioética y derechos humanos. Bogota: Ediciones del Bosque, 1998. (Colección Bios y Ethos).

INFORME de la Comisión sobre Derechos de Propiedad Intelectual del Reino Unido. In: Temas de Derecho Industrial y de la Competencia, n. 7. Buenos Aires: Ciudad Argentina, 2005.

MALDONADO, C. E. Necesidad de esencia y comunidad de problemas de la bioética y los derechos humanos. In: Escobar Triana, J. Y et al. (Orgs.). Bioética y derechos humanos. Bogota: Ediciones del Bosque, 1998. (Colección Bios y Ethos).

PATRÃO NEVES, M. do Céu. Alocação de recursos em saúde: considerações éticas. Bioética, Brasilia, v. 7, n. 2, 1999.

PECUL, $V$. Los gobiernos deben responsabilizarse por tratar las enfermedades olvidadas. El País, Madrid, 18 abr. 2006.

PETER, F.; Evans, T. Dimensiones de la equidad en salud: In: AA. Desafío de la falta de equidad en la salud. Washington: OPS, 2000.

REIS, A. L. de Almeida dos; BERMÚDEZ, J. Aspectos económicos: mercados farmacéuticos y precio de medicamentos. In: BERMÚDEZ, J.; OLIVEIRA, M. A.; ESHER, A. Acceso a medicamentos: derecho fundamental: papel del Estado. Rio de Janeiro: Fiocruz, 2004.

REMICHE, B. Les brévets farmaceutiques entre l'interêt privé et public: un equilibre imposible? Révue Internationale de Droit Économique, v. 1, 2000.

ROSSI, F. Enfermedades de alto impacto social, enfermedades olvidadas, medicamentos de alto costo y ARV. In: BERMÚDEZ, J.; OLIVEIRA, M. A.; ESHER, A. Acceso a medicamentos: derecho fundamental: papel del Estado. Rio de Janeiro: Fiocruz, 2004. 
SCHRAMM, F. R. Bioética sin universalidad. Justificación de una bioética latinoamericana y caribeña de protección. In: GARRAFA, V.; KOTTOW, M.; SAADA, A. (Coords.). Estatuto epistemológico de la bioética. México: UNAM, 2005.

SEÚBE HERNÁNDEZ, X. El Derecho al acceso a los medicamentos esenciales $y$ el comercio internacional de productos farmacéuticos. 2004. (Tesis) Universidad Pompeu Fabra, Barcelona, 2004. Inédito.

SILVA, C. dos Santos; ZEPEDA BERMÚDEZ, J. Medicamentos excepcionais ou de alto custo no Brasil. In: BERMÚDEZ, J.; OLIVEIRA, M. A.; ESHER, A. Acceso a medicamentos: derecho fundamental: papel del Estado. Rio de Janeiro: Fiocruz, 2004.

TAPAJÓS, A. M. Patentes e asesso a medicamentos: estudio bioético de la Declaração de Doha. 2005. (Tesis). Brasilia 2005. Inédito.

VELÁSQUEZ, E. Médicaments essencials et mondialisation. Revue International de Droit Économique, v. 1, 2000.

VELÁSQUEZ, Germán. El papel del Estado en el financiamiento de los medicamentos. In: BERMÚDEZ, J.; OLIVEIRA, M. A.; ESHER, A. Acceso a medicamentos. derecho fundamental: papel del Estado. Rio de Janeiro: Fiocruz, 2004.

VELÁSQUEZ, Germán; CORREA, Carlos M.; BALASUBRAMANIAM, Thirkumarann. La OMS al frente de la lucha por el acceso a los medicamentos. In: BERMÚDEZ, J.; OLIVEIRA, M. A.; ESHER, A. Acceso a medicamentos: derecho fundamental: papel del Estado. Rio de Janeiro: Fiocruz, 2004.

ZATTI, R. Verso un diritto per la bioética. In: MAZZONI, C. M. (a cura di). Una norma giuridica per la bioética. Bologna: II Mulino, 1988.

\section{VERSÃO EM PORTUGUES}

\section{Bioética e o Direito de Acesso aos Medicamentos}

\section{UMA NOVA VISÃO DA BIOÉTICA}

A abordagem ética do acesso aos medicamentos envolve aspectos políticos, econômicos e jurídicos que - em uma análise preliminar - poderiam parecer exorbitantes ao campo da indagação. Para entender a postura que aqui assumimos, incluindo tais aspectos, é necessário referirmos à recente evolução da bioética.

Berlinguer, um dos bioetecistas atualmente mais destacados, assinala em um dos seus lúcidos artigos que "o tema saúde raramente está presente 
no debate bioético; Ihe é geralmente negado o título de nobreza como objeto da ética e, no melhor dos casos, Ihe é atribuído somente o valor (que para alguns é considerado filosoficamente irrelevante e intelectualmente popular) de questão social"(42). É que os debates bioéticos transcorrem geralmente em torno de problemas "mais específicos e mais atuais", como o da fecundação assistida, os dilemas da nova genética, os transplantes de órgãos, os limites dos cuidados intensivos, a pesquisa de embriōes etc. Sem desconhecer a importância que assumem estes temas, não podemos deixar de advertir que os problemas vinculados à saúde coletiva, junto aos fatores que a condicionam, deveriam estar no centro da reflexão bioética, para que esta disciplina de curta história não se transforme em algo desvinculado da realidade que envolve milhões de homens.

Cabe recordar que a bioética nasceu e foi cultivada nos países do norte com uma acentuada tendência que privilegiou os problemas e os dilemas nascidos da pesquisa médica em um momento de profundas transformações originadas no salto espetacular das ciências biológicas e médicas, a partir da segunda metade do último século. Em seguida, cabe observar que o desenvolvimento recente dos estudos bioéticos não é somente patrimônio dos países do norte, mas que, em um plano mais universal, a disciplina foi ampliando consideravelmente seus domínios ao incorporar temas que pareciam pertencer ao campo econômico-social, mas que em definitivo guardam estreita relação com a vida dos homens. Faz algum tempo que, com ênfase crescente, foram incorporados ao seu campo de reflexão temas como a pobreza, a fome, a exclusão social, a desnutrição, o acesso à água potável etc.

Diante disso, não podemos inferir que a bioética esteja invadindo os campos reservados à política ${ }^{(43)}$. Simplesmente é necessário reconhecer que as políticas econômicas e sociais estão indissoluvelmente ligadas a sua esfera de interesse. Nessa linha, compartilhamos com $R$. Zatti que "a cena moderna configura uma nova imagem da bioética: não somente um "ramo do conhecimento" mas uma experiência multiforme de formação do consenso em torno dos problemas, escolhas morais, opções políticas ou legais que apontam a relação entre a ciência e os valores do homem"(44).

Falar de uma doença, ignorando os fatores ligados a sua origem e desenvolvimento, ou considerar o sujeito como algo dissociado das circunstâncias econômicas e sociais que condicionam sua vida, importam, pelo menos, em cair num reducionismo distante da realidade vital. Desde os anos 70 do século passado - considerado como a data de nascimento

(42) BERLINGER, G. Ética de la salud. Buenos Aires: Lugar Edit., 1996. p. 17.

(43) Garrafa esclarece o campo da controvérsia: a bioética incursiona na política para incluir as perguntas sociais em sua agenda. Isso não é biopolítico. É a bioética intervindo na dimensão mais ampla: a política (GARRAFA, V. Inclusão social no contexto político da bioética. Revista Brasileira de Bioética, v. 1, n. 2, p. 122, 2005).

(44) ZATTI, R. Verso un diritto per la bioética. In:MAZZONI, C. M. (a cura di). Una norma giuridica per la bioética. Bologna: II Mulino, 1988. p. 63. 
desta disciplina - até o presente, foi visualizada uma série de grandes problemas e dilemas. $O$ avanço e o reaparecimento de doenças vinculadas à exclusão social, fruto do abandono do estado de bem-estar, e da generalização das políticas econômicas neoconservadoras, que agravaram os problemas gerados pela pobreza e pela fome (que restringem consideravelmente as possibilidades de acesso aos serviços de saúde), levou os cultuadores da bioética a assumirem posições mais radicais para dar um perfil de acordo com a realidade social em que se opera. Esta tendência teve um desenvolvimento notável na América Latina. Aqui surgiram posições que demonstram uma "bioética da intervenção" e uma "bioética da proteção", com um sentido político e social notável que aponta para um maior nível de compromisso com os problemas sociais abundantes na região e comuns a outras regiões do terceiro mundo ${ }^{(45)}$. A recente Declaração Universal sobre a Bioética e os Direitos Humanos da UNESCO, de 12 de outubro de 2005, dá um claro respaldo a essas posturas quando destacam temas como a fome, a exclusão social, a desnutrição, a saúde pública e o acesso à saúde e aos medicamentos (em especial o art. 14, intitulado "responsabilidade social em saúde"). Partindo dessa nova realidade, examinaremos o tema do acesso a medicamentos com um enfoque que, sem desconhecer que nos movimentamos no campo da bioética, contemple as políticas públicas que tematizam essa matéria.

\section{O DIREITO À VIDA, À SAÚDE E AO ACESSO AOS SERVIÇOS DE SAÚDE E MEDICAMENTOS}

Considero que, antes de entrar na consideração particular de cada um dos direitos enunciados no título, vale a pena explicar as razões que justificam trazer a este debate a teoria dos direitos humanos.

Como ensina Hottois(46), a problemática chamada hoje de "bioética" chegou a se confundir, há 50 anos, com a questão dos direitos humanos,

(45) A bioética da intervenção - na opinião de Garrafa - identifica e incorpora a dimensão social da pessoa como uma totalidade somática na qual estão articuladas as dimensões físicas e psíquicas que se manifestam de maneira integrada nas relações sociais e nas relações com o ambiente (op. cit., p. 127). A bioética da proteção, de acordo com Schramm, foi pensada inicialmente como uma resposta aos conflitos morais que se dão no campo da saúde e da qualidade de vida dos indivíduos e populações que, por uma razão ou outra, não estavam (e não estão) "cobertos" em seus direitos de cidadão; quer dizer, pensada para proteger àqueles que, por suas condições objetivas de vida e/ou saúde, são suscetíveis ou fragilizados ao ponto de não desenvolverem seus potencias e projetos legítimos de vida normalmente legítimos; porque as políticas públicas da saúde não os garantiram. É uma ética aplicada em nível mínimo, ou do "primeiro nível" (como escreve Atalán), algo como uma condição necessária para dizer que estamos no campo da ética e para que essas pessoas fragilizadas e/ou suscetíveis tenham alguma alguma possibilidade de viver com dignidade e de realizar seus projetos razoáveis de vida compartilhada com a sociedade (SCHRAMM, F. R. Bioética sin universalidad. Justificación de una bioética latinoamericana y caribeña de protección. In:GARRAFA, V.; Kottow, M.; SAADA, A. (Coords.). Estatuto epistemológico de la bioética. México: UNAM, 2005. p. 165).

(46) HOTTOIS; G. Bioética y derechos humanos. In: ESCOBAR Triana, J. Y et al. (Orgs). Bioética y derechos humanos. Bogota: Ediciones del Bosque, 1998. p. 151. (Colección Bios y Ethos). 
agregando que "os direitos humanos constituem um sólido muro de contenção contra toda vontade - realista ou não - de registrar biologicamente (genética e hereditariamente) na humanidade diferenças hierarquizantes que resultem, de maneira aberta ou não, na distinção de indivíduos, uns com menor valor e outros com maior valor. A igualdade também implica em uma preocupação de eqüidade, que faz com que os direitos humanos caminhem na direção de um acesso igual para todas as fontes e meios da biomedicina". $\mathrm{E}$, em sintonia com esta posição, Maldonado agrega que "é preciso dizer que os direitos humanos não são uma preocupação especialmente jurídica, nem mesmo no sentido mais generoso da palavra, já que, pelo contrário, são uma preocupação eminentemente ética e, só porque é ética, é adicionalmente um assunto político, jurídico e econômico"(47).

$\mathrm{Na}$ análise do assunto que nos ocupa, existem três direitos humanos que, apesar de guardarem uma íntima e direta relação, apresentam características próprias. O primeiro dos direitos referidos, o direito à vida, é mais amplo, tanto que não é possível falar de saúde nem de acesso aos serviços da saúde ou aos medicamentos se não se contemplar a própria vidạ. A Declaraçăo Universal dos Direitos Humanos reconhece, em seu art. $3^{\circ}$, que "todo o indivíduo tem direito à vida, à liberdade e à segurança de sua pessoa". Contra a caracterização tradicional do direito à vida, como um direito para cuja satisfação basta que o Estado não atente contra a vida de seus habitantes, existe um conjunto amplo de obrigações que requer a atividade positiva do Estado. Neste sentido, a colocação do direito à vida entre os direitos civis e políticos não restringe o caráter das obrigações referidas. Como Seúbe recorda, tanto a doutrina, como a prática jurisprudencial deixaram a missão restritiva do direito à vida, que limita as obrigações dos Estados a não atentar contra a vida das pessoas, e começaram a indicar as obrigações positivas que dele derivam. Entre outros fatores, nesta evolução influenciaram tanto a evidência de que não se pode dissociar o direito à vida da morte de milhares de pessoas ao ano por inanição ou à falta de acesso aos medicamentos, como a implementação da noção de interdependência e indivisibilidade dos direitos humanos ${ }^{(48)}$.

Estreitamente vinculado ao direito à vida se encontra o direito à saúde, recepcionado no art. 25 da Declaração Universal dos Direitos Humanos, nestes termos: "toda a pessoa tem direito a um nível apropriado que the assegure, assim como à sua família, a saúde e o bem-estar e em especial a alimentação, o vestuário, a assistência médica e os serviços sociais necessários." Dois anos antes de proclamada a Declaração, na introdução dos estatutos da Organização Mundial de Saúde (OMS) podia-se ler que "o bene-

(47) Maldonado, C. E. Necesidad de esencia y comunidad de problemas de la bioética y los derechos humanos. In: Escobar Triana, J. Y et al. (Orgs). op. cit., p. 95.

(48) Seúbe Hernández, X. El Derecho al acceso a los medicamentos esenciales y el comercio internacional de productos farmacéuticos. 2004. (Tesis) — Universidad Pompeu Fabra, Barcelona, 2004. Inédito. 
fício de gozar de níveis elevados de saúde é um dos direitos fundamentais do ser humano, sem distinção de raça, de religião, de credo político, condição social ou econômica".

O direito à saúde, como outros econômicos e sociais, vem precedido por certo hálito de ineficácia; estigma que tem por origem as dúvidas sobre sua justicialidade e que se manifesta - ao dizer de Seúbe - em problemas concretos de clareza conceitual e de sobreposição com outros direitos. A esta concepção não é estranha uma visão fragmentada dos direitos humanos, que coloca os direitos econômicos e sociais em um plano inferior aos civis e políticos ${ }^{(49)}$. Um dos argumentos que são repetidos para manter a pretendida distinção dos direitos civis e políticos com respeito aos econômicos, sociais e culturais, repousa na suposta característica de obrigações negativas da primeira espécie de direito, enquanto que a segunda implicaria o nascimento de obrigações positivas que na maioria dos casos devem ser resolvidas com recursos do Erário Público(50).

De acordo com uma concepção que conta com muitos seguidores, a força vinculante, a exigibilidade ou mesmo a própria juridicidade dos direitos econômicos, sociais e culturais é duvidosa, já que a satisfação destes depende da disponibilidade de recursos por parte do Estado. Este alegado "condicionante econômico" tornaria relativa a universalidade dos direitos de massas, condenando-os a ser de "segunda categoria". Não obstante adicionam Abramovich e Courtis - se observarmos a evolução das funções e dos papéis do Estado na gestação e na promoção dos direitos civis e políticos poderemos perceber que tais atividades não estão confinadas à mera função passiva de não interferir em seu gozo. Desta perspectiva, as diferenças entre direitos civis e políticos por um lado e direitos econômicos, sociais e culturais por outro, longe de ser substanciais, apontam para um maior ou menor grau de intervenção(51).

Além de reconhecer que as facetas mais visíveis dos direitos econômicos, sociais e culturais são obrigações de fazer, o que conduziu a denominá-los "direitos-proteção", não é possível reconhecer diferenças relevantes. Contreras Peláez, considerando a impossibilidade da distinção clara entre ambos os tipos de direitos, sustentou que para os direitos sociais a prestação estatal representa verdadeiramente a substância, o núcleo, o conteúdo essencial do direito. Mas, é o caso de notar que muitos direitos fundamentais incluídos no catálogo dos civis e políticos foram reinterpretados em chave social, de modo que as distâncias perdem absolutamente o sentido nestes $\operatorname{casos}^{(52)}$.

(49) Id. Ibid.

(50) ABRAMOVICH, V.; COUTIS, C. Hacia la exigibilidad de los derechos económicos, sociales y culturales. In: Abregú, M.; Coutis, C. Aplicación de los Tratados sobre derechos humanos por jueces locales. Buenos Aires: Editorial del Puerto, 1997. p. 2.

(51) Id. Ibid., p. 8.

(52) Id. Ibid., p. 4. 
Embora a função de prestação positiva nos direitos econômicos e sociais seja importante, não podemos negar que o desenvolvimento das políticas de Estado que não requerem prestações traduzidas em dispêndios econômicos contribui decisivamente para o gozo daqueles. Sirva como o exemplo o regulamento sobre medicamentos genéricos que abaixa sensivelmente seu preço de custo, sem afetar sua qualidade e eficácia. Reconhecida a categoria de direitos econômicos e sociais que ostentam, é possível recordar que o art. 2.1 do Pacto Internacional dos Direitos Econômicos, Sociais e Culturais estabelece o compromisso de adotar medidas até o máximo dos recursos que se disponha, para obter progressivamente, por todos os meios apropriados, inclusive, em especial, a adoção de medidas legislativas, a plena eficácia dos direitos, o que envolve a progressividade, vinculada estreitamente com a proibição da regressividade.

Berlinguer relaciona o direito à saúde com o direito à assistência sanitária. Deve-se reconhecer - em sua opinião - que conformam dois aspectos estreitamente unidos entre si, mas diferentes em sua origem, por sua construção ética e por sua forma de agir(53). $O$ acesso aos serviços da saúde é um direito ao qual se deve reconhecer uma configuração própria, derivada do genérico direito à saúde. Quando a saúde falha - por diversas razões que não vêm ao caso mencionar - chega a hora da verdade para que se veja realizado de fato o direito reconhecido. O auxílio médico oportuno, apropriado às circunstâncias do caso e de qualidade, responde pelo princípio ético da eqüidade na esfera sanitária. Este direito deve ser de alcance universal. Não é possível sustentar a existência de graus diversos de atenção de acordo com as particularidades do caso, ou à posição do sujeito no plano social, sem que se comecem a enfatizar as relações intrincadas entre o mercado e a saúde, que freqüentemente impedem o sucesso destas premissas.

Finalmente devemos nos referir ao assunto que desperta nossa atenção: o direito ao acesso aos medicamentos. Não é possível falar de direito à vida ou à saúde sem envolver o acesso aos medicamentos, acesso que não se esgota com a simples provisão àquele que dele necessita. Tal acesso deve possibilitar o cumprimento da função que ele deve desempenhar na órbita sanitária, para o qual deve convergir uma série de requisitos: 1) que o acesso seja oportuno, quer dizer, que a provisão chegue a tempo para poder exercer sua função terapêutica; 2) que seja de qualidade e na quantidade devida. Isto impõe o cumprimento de funções indelegáveis por parte do Estado no que concerne ao controle de qualidade e, paralelamente, à garantia da provisão durante todo o tempo necessário, com relação à causa que a gera $^{(54)}$; 3) que quem o acesse se encontre em condições para suportar seu

(53) BERLINGER, G. op. cit., p. 62.

(54) Menos de um terço dos países pobres têm autoridades regulatórias e em muitos destes países uma amostra de $10 \%$ a $30 \%$ dos medicamentos não atendem às condições mínimas da qualidade. A ausência de boas práticas de fabricação e de fiscalização apropriada leva, freqüentemente, à elaboração de produtos tóxicos e às vezes letais. A expansão do comércio de medicamentos tem em si mesma desa- 
custo sem ver afetadas significativamente suas condições de vida. Isto é importante principalmente se tomarmos em consideração que as inovações no campo da indústria farmacêutica têm um custo elevado, que em geral não guardam relação com a renda dos pacientes; 4) que quem acesse a sua provisão tenha um nível apropriado de informação. A informação é relevante para o uso racional dos medicamentos, a fim de evitar o consumo de drogas que não cumprem uma função terapêutica para o caso, ou o que é mais grave ainda possam causar conseqüências prejudiciais para o consumidor; 5) que o medicamento seja eficaz para o uso ao qual é destinado. Ana Maria Tapajós indica que o acesso aos medicamentos se insere no quadro mais amplo que envolve a promoção da saúde, a prevenção e a recuperação. Desta forma, é o mesmo não ter acesso aos serviços, como ter acesso a serviços sem eficácia(55). A provisão de medicamentos inadequados ou em doses superiores à necessária pode conduzir à criação de resistência aos agentes patogênicos, o que, por sua vez, compromete o futuro da saúde do usuário.

Um medicamento - ensina Rossi - é o resultado de unir ao produto uma informação e um contexto. Em um contexto dado não somente contam os regulamentos específicos, mas, a forma de organização social, "a ordem econômica global" e a organização dos serviços da saúde. Estamos falando de política ${ }^{(56)}$. $O$ acesso aos medicamentos deve, necessariamente, ser analisado e discutido no âmbito geral das políticas sanitárias, já que, de outra forma, caímos na simplificação - inaceitável por certo - de deixar o mercado como regulador e árbitro da saúde coletiva, esquecendo-se do compromisso primordial do Estado para com a sociedade. Na opinião de Germán Velázquez o Estado deve assumir a responsabilidade complementar de um conjunto de funções básicas no setor farmacêutico: elaboração de políticas de financiamento, regulação em matéria de medicamentos, estabelecimento de normas profissionais, promoção do uso racional dos medicamentos etc. Estas funções constituem o mínimo do que o Estado deve fazer ${ }^{(57)}$. Deve ficar claro que não basta a contribuição econômica do Estado através de diversas vias: compras maciças, subsídios, provisão gratuita etc. É essencial que tal contribuição - válida por certo - seja complementada com outras ações de não menos importância.

Os mercados de medicamentos requerem uma corrente da informação completa entre os compradores e os fornecedores. O desequilíbrio da infor-

fios para assegurar padrōes globais de qualidade. (TAPAJÓS, A. M. Patentes e asesso a medicamentos. estudio bioético de la Declaração de Doha. 2005. (Tesis). Brasilia 2005. Inédito).

(55) Id. Ibid.

(56) Rossi, F. Enfermedades de alto impacto social, enfermedades olvidadas, medicamentos de alto costo y ARV. In:BERMÚDEZ, J.; OLIVEIRA, M. A.; ESHER, A. Acceso a medicamentos derecho fundamental: papel del Estado. Rio de Janeiro: Fiocruz, 2004. p. 193.

(57) VELÁSQUEZ, Germán. El papel del Estado en el financiamiento de los medicamentos. In:BERMÚDEZ, J.; OLIVEIRA, M. A.; ESHER, A. op. cit., p. 32. 
mação entre os produtores de medicamentos e os fornecedores dos serviços de saúde e entre estes e os pacientes é uma das causas principais da falha no mercado de produtos farmacêuticos ${ }^{(58)}$. As diferenças entre o mercado dos serviços de saúde e os medicamentos e outros mercados (desequilíbrio de informação, escassa concorrência, externalidade e objetivos distintos de lucro), justifica amplamente a intervenção do Estado a fim de restabelecer o necessário equilíbrio entre as partes.

Verifica-se, do até aqui resvisto, que o direito humano ao acesso aos medicamentos implica na colocação em marcha de mecanismos complexos com a intervenção de atores diversos, entre os quais prima o Estado como garantidor da saúde coletiva.

\section{O PAPEL DO ESTADO}

Indicamos que a função do Estado em torno do acesso aos medicamentos não se pode limitar a uma posição passiva e que longe de se esgotar com a entrega material do medicamento àquele que o necessita, liga-se a uma série de obrigações que convergem realmente a uma proteção apropriada da saúde pública, traduzida na formulação de políticas sanitárias ${ }^{(59)}$.

É importante assegurar a qualidade dos medicamentos, dispondo-se de controles apropriados, além de assegurar seu uso racional. Em 1985, durante a Conferência Mundial sobre o uso racional dos medicamentos, realizada em Nairóbi, estabeleceu-se que o uso racional existe quando os pacientes recebem medicamentos apropriados a suas necessidades clínicas, nas doses adaptadas às particularidades individuais, por período de tempo apropriado e com custo baixo para eles e sua comunidade. É natural que o uso racional esteja relacionado às políticas de informação e educação. Mas, talvez o assunto mais relevante para esta análise seja o custo do medicamento, condicionante que, no limite, transforma-se na barreira principal para o acesso. O Estado deve intervir por meio da execução das políticas ajustadas na provisão, controle de qualidade, racionalidade no uso e na fixação dos preços.

Sem desconhecer os limites fixados pelo sistema da economia de mercado é possível desenvolver políticas que conduzam à fixação de preços razoáveis e evitar a especulação que, no extremo, converte-se em uma privação do acesso a grandes setores da população. Considerando o caráter de

(58) /d. Ibid., p. 25.

(59) Os objetivos de saúde pública e os interesses comerciais das indústrias às vezes coincidem e às vezes divergem. Não são idênticos. Quando entram em colisão, deveriam ser sempre capazes de optar pela saúde pública como uma razão legítima de limitar ou condicionar os interesses e direitos comerciais. (Zafar, M., en: WHO/DAP/98.9). 
bem público que atribuímos ao medicamento, tais políticas regulatórias implicam não somente em uma faculdade legítima dos Estados, mas, se tornam um dever inescusável, já que a saúde coletiva não pode ser deixada ao sabor das oscilações de uma indústria que não reconhece limites a seus apetites de lucro.

Demonstrou-se que a redução dos preços está em relação direta com o número dos pacientes que têm acesso aos medicamentos, aqueles que, em suposição contrária, seriam privados das terapias para combater o mal de que sofrem. Um estudo feito em Uganda estimou que, reduzindo o preço de uma terapia tripla de anti-retrovirais de US\$ 6 mil para US $\$ 600$ ao ano, a demanda de tratamento seria aumentada de mil para 50 mil pacientes. Similarmente, um estudo econométrico mundial calculou que, se fossem eliminadas as patentes de uma amostra representativa dos países em desenvolvimento, se obteria um aumento do acesso às terapias anti-retrovirais de $30 \%\left({ }^{(60)}\right.$.

Diversas são as políticas que pode experimentar o Estado nessa direção. Uma das mais eficazes é a que visa facilitar a concorrência através dos medicamentos genéricos. O medicamento genérico é um produto farmacêutico que se considera permutável com o produto inovador e que se costuma fabricar sem a licença da companhia inovadora e comercializar uma vez expirada a patente ou outros direitos de exclusividade ${ }^{(61)}$. Com a caducidade das patentes pelo mero decurso de prazo de validade, os medicamentos experimentam uma contínua erosão da relativa inelasticidade preço-demanda, resultante da discriminação notável de diferenciação dos produtos, uma vez que os medicamentos genéricos lançados são iguais aos produtos invocados, desviando a concorrência para o preço. As políticas de genéricos, experimentadas em vários países, tornaram possível uma diminuição sensível dos preços uma vez que supera a patente.

Uma outra forma de intervenção consiste na facilitação de importações paralelas dos mercados em que, tendo entrado legalmente, o medicamento é vendido a um preço menor do que o comercializado no país. Também conceder licenças compulsórias constitui outra das armas que o Estado pode utilizar para lutar contra uma especulação abusiva. O próprio Acordo TRIPS (Agreement on Trade-Related Aspects of Intellectual Property Rights, em português "Acordo sobre Aspectos de Direitos de Propriedade Intelectual Relacionados ao Comércio) autoriza conceder licenças compulsórias para restaurar a concorrência em caso do abuso da posição dominante das companhias farmacêuticas, traduzido na fixação de preços exorbitantes. As condições severas as quais o Acordo submete a concessão de tais licenças constituem um obstáculo sério a seu uso. A flexibilização dessas

(60) INFORME de la Comisión sobre Derechos de Propiedad Intelectual del Reino Unido. In: Temas de Derecho Industrial y de la Competencia, n. 7. Buenos Aires: Ciudad Argentina, 2005. p. 122.

(61) WHO/DAP/98.9. 
condições - tal como observou a Declaração de Doha - constitui um objetivo importante a ser alcançado pelos países menos desenvolvidos. O relatório da Comissão sobre os Direitos de Propriedade Industrial do Reino Unido recomendou que os países devem adotar uma variedade de políticas para melhorar o acesso aos medicamentos, indicando que se deve harmonizar outras políticas macroeconômicas e o sistema de propriedade intelectual com os objetivos das políticas de saúde ${ }^{(62)}$.

\section{OS "MEDICAMENTOS-ORFÃOS" E DE ALTO CUSTO}

Uma questão importante que toca no campo da justiça global é o que apresentam os denominados "medicamentos-órfãos", problema que põe a nu a referida dupla função do medicamento, como bem social e mercadoria. O termo foi usado pela primeira vez em 1968 para se referir às drogas potencialmente úteis que não estão disponiveis no mercado por não serem lucrativas, e se alargou, posteriormente, para designar a inexistência de medicamentos para combater às novas doenças peculiares ou preponderantes nos países pobres ${ }^{(63)}$.

Não se trata de barreiras existentes para o acesso aos medicamentos disponiveis no mercado, mas da falta de produção ou de distribuição de medicamentos para lutar contra as doenças da pobreza que - na opinião do mercado - não oferecem um rendimento aceitável(64). Isso nos aproxima das chamadas "doenças esquecidas", patologias que não são outras que as doenças dos homens pobres dos países pobres - em especial daqueles situados no Trópico - e que são estreitamente relacionadas às míseras condições de vida de grandes massas da população, que não chegam a constituir um mercado, uma vez que, mesmo partindo da existência de uma demanda, os interessados não têm meios de participar dele ${ }^{(65)}$.

Entre as doenças esquecidas, os países desenvolvidos e subdesenvolvidos apresentam uma série de males tais como a malária, dengue, mal de chagas, leishmaniose, além de certos tipos de problemas respiratórios agudos, que, no limite, constituem a causa maior de morte em setores caren-

(62) INFORME de la Comisión sobre Derechos de Propiedad Intelectual del Reino Unido, cit., p. 128.

(63) SILVA, C. dos Santos; ZEPEDA BERMÚDEZ, J. Medicamentos esepcionais ou de alto custo no Brasil. In:BERMÚDEZ, J.; OLIVEIRA, M. A.; ESHER, A. op. cit., p. 203.

(64) Cabe destacar a forma pela qual os países tratam o tema dos chamados medicamentos-órfãos. Nos Estados Unidos, desde 1982, estabeleceu-se um sistema de promoção dos medicamentos-órfãos (Orphan Drug Act/Food and Drug Administration - ODA/FDA), iniciativa que foi seguida por outros países como Japão, Austrália e os da União Européia. Por razões óbvias, os países subdesenvolvidos viram-se obrigados a adotar tal sistema. Nos casos citados, os medicamentos-órfãos receberam, como incentivos federais, subsídios do Congresso, um período de exclusividade de comercialização e isenção de impostos.

(65) ROSSI, F. op. cit., p. 195. 
tes. Se for verdade que historicamente as patentes estimularam a descoberta de medicamentos novos, cabe destacar que a indústria farmacêutica está submetida aos imperativos do mercado. Daí que os medicamentos novos colocados no mercado não são, exatamente, os mais apropriados para as finalidades terapêuticas da maioria da população mundial(66).

A análise desse assunto não somente põe em evidência a falta de interesse na eventual produção e comercialização das drogas por parte da indústria farmacêutica multinacional - conduta em si mesma reprovável - mas, que é necessário adicionar um ingrediente complementar: a falta de interesse dos centros de pesquisa dos países desenvolvidos em cuidar das doenças da pobreza ${ }^{(67)}$. Entre 1975 e 2004, foram comercializados 1.556 novas drogas e somente 20 delas (1.3\%) tratam enfermidades tropicais. Acrescente-se a isso o fato de que vários dos medicamentos existentes não estão adaptados à situação particular dos países ${ }^{(68)}$.

Neste sentido, Iván llich indicou que "a maioria dos estabelecimentos de investigação se reservam a investigadores programados para interpretar 0 mundo em termos de ganho e poder e a maioria dos fins da investigação se determina por motivos de poder e de eficiência. Esta é uma reflexão que deveria se incorporar aos debates sobre a propriedade intelectual no setor farmacêutico". Seria necessário considerar o acima afirmado para buscar os promotores da indústria farmacêutica multinacional quando pretendem fundamentar seus ganhos exorbitantes na necessidade de contar com fundos "para continuar investigando". Dever-se-ia interrogar sobre os critérios de seleção de tais investigações ${ }^{(69)}$.

Sendo que, como ressaltamos, os medicamentos constituem um bem social e que em sua provisão estão comprometidas políticas essenciais e irrecusáveis do Estado, não podemos falar do acesso aos medicamentos sem incluir os "medicamentos-órfãos". O acesso aos medicamentos não pode

(66) VELÁSQUEZ, E. Médicaments essencials et mondialisation. Revue International de Droit Economique, v. 1, 2000.p. 38.

(67) Cabe assinalar que recentemente a iniciativa dos Médicos Sem-Fronteiras de criar um grupo de trabalho para medicamentos de doenças esquecidas apresentou algumas recomendações para acabar com o impasse: estabelecer uma agenda global de pesquisas bem definida e motivada por necessidades; empenho na busca de soluções por parte dos governos que devem cumprir suas responsabilidades, aumentando a formação de pesquisadores das doenças esquecidas e a criação de uma instituição sem fins lucrativos para fiscalizar a deficiência em pesquisa e desenvolvimento das doenças esquecidas.

(68) PECUL, V. Los gobiernos deben responsabilizarse por tratar las enfermedades olvidadas. El País, Madrid, 18 abr. 2006.

(69) Um dos principais argumentos em prol das patentes farmacêuticas é o de que elas são necessários para a pesquisa e desenvolvimento. Não obstante, nos países em desenvolvimento $75 \%$ da população mundial consome somente $14 \%$ da oferta mundial de medicamentos. E $15 \%$ da população dos países industrializados consome $86 \%$. As políticas de livre comércio e os acordos comerciais não estarão enfrentando os problemas de mercado, enquanto não desenvolverem e comercializarem medicamentos acessiveis para as doenças que mais incidem nas regiōes pobres como a tuberculose, malária e a AIDS. (Mirza Zafer, en: WHO/DAP/98.9). 
limitar-se ao que fornece o mercado farmacêutico, uma vez que a saúde pública não pode ser subordinada aos estritos fins econômicos que perseguem as companhias farmacêuticas. Se não existe na indústria interesse em produzir e comercializar determinadas drogas, essa tarefa deve ser assumida prioritariamente pelo Estado, pessoalmente, ou através de organismos que the são ligados.

Também, entre os deveres que deve assumir o Estado quanto à proteção e à promoção da saúde pública, é preciso incorporar a realização de investigações orientadas à erradicação das doenças que não contam com terapias apropriadas. Nesta linha, a 56aㅗ Assembléia Mundial da Saúde, advertindo que a investigação e o desenvolvimento no setor farmacêutico devem responder às necessidades da saúde pública e não somente às possibilidades de obter benefícios comerciais, incitou os Estados-membros a procurarem criar as condições favoráveis para a investigação e o desenvolvimento de medicamentos novos contra as doenças que afetam os países menos avançados. Os países subdesenvolvidos vítimas de muitas delas devem adotar uma posição ativa, desenvolvendo planos de pesquisa com outros países que ajudem na busca de medicamentos eficazes para tais fins.

\section{OS CRITÉRIOS DE JUSTIÇA, EQÜIDADE E SOLIDARIEDADE NO ACESSO AOS MEDICAMENTOS}

A atenção à saúde compreende a assistência médica, a qual, por sua vez, inclui os estágios em cujo desenvolvimento aparece necessariamente o tema do acesso aos medicamentos. As disparidades sociais que apresenta a desigualdade de renda e de oportunidades na população fazem com que se esqueça o ideal de justiça como meta a ser alcançada no acesso aos medicamentos, pois o tratamento igualitário entre aqueles que possuem pontos de partida diferentes conspira contra o alcance da finalidade proposta. Daí que seja mais adequado à realidade ajustar-se ao conceito de eqüidade, que busca que os iguais sejam tratados de forma igual e que os desiguais, de forma desigual. Dessa maneira a eqüidade se converte em um princípio comparativo, em um critério sobre a situação que a pessoa ou o grupo de pessoas ocupam em relação com os demais, favorecendo uma espécie de discriminação positiva(70).

A aplicação de critérios de justiça rígida, indiferenciada, distancia-se dos matizes concretos que apresenta cada situação em particular e somente pode conduzir a consagrar nos fatos verdadeiras injustiças. Se o que se pretende é levar para todos um sistema de atenção eficaz e eficiente, não há

(70) PETER, F.; EVANS, T. Dimensiones de la equidad en salud: In: AA. Desafío de la falta de equidad en la salud. Washington: OPS, 2000. p. 290. 
outra maneira senão considerando as diferenças que são observadas na sociedade. A premissa - já se indicou - é que a eqüidade no campo da saúde não pode ser um conceito apolítico, acultural, tecnocrático, limitado ao campo da assistência médica ou ao da saúde pública. A melhor forma para considerar a eqüidade no campo da saúde não é como um objetivo social em si mesmo e isolado, senão que como algo inerente à busca de uma forma ampla de justiça social|(71).

Quando a OMS lança o plano de medicamentos essenciais com acesso irrestrito aos cidadãos do mundo; quando se aponta para fazer flexível o regime das patentes para possibilitar o acesso dos povos atingidos pela pandemia da AIDS às drogas retrovirais; quando se impele o oferecimento de medicamentos genéricos a preços acessíveis; se está recorrendo aos critérios de eqüidade para fazer efetiva a justiça social tanto em nível interno quanto em nível global.

Considerar a saúde como o resultado do acaso biológico separado da multiplicidade de fatores socioeconômicos que a condicionam e que, em grau significativo, a determinam, apenas conduz a uma visão superficial, reducionista, não comprometida, que separa da análise os dados mais significativos e enriquecedores. Partindo das naturais diferenças biológicas entre os indivíduos - que não podem ser evitadas pela ação humana - resta um amplo campo aos problemas "evitáveis" com o esforço comum dos homens e dos povos; um espaço reservado à solidariedade.

O princípio de eqüidade apela ao princípio de solidariedade como a condição de sua efetivação: a igualdade de direitos entre todos os homens somente pode ser restaurada de fato, se também todos os homens redistribuírem todos os seus bens entre si. E a saúde não pode se constituir numa exceção a tais critérios gerais ${ }^{(72)}$. Nesta linha Rossi destaca que 0 princípio de distribuir pelos custos (o princípio de solidariedade) de acordo com a renda de cada um e dos eventos de doença (princípio de eqüidade), assumindo desse modo que os problemas de saúde são de "todos" e os rateamos entre "todos" de acordo com a capacidade de cada um, constitui um enorme avanço(73).

Em 1975, a Assembléia Mundial da Saúde, frente à crise que atingia os países em desenvolvimento, causada pelo custo elevado dos medicamentos, que impossibilitava seu acesso, adotou uma definição em que, pela primeira vez, são introduzidos os conceitos de "política farmacêutica nacional" e de "medicamentos essenciais" no vocabulário da saúde pública internacional. De conformidade com isso, em 1981, a OMS criou o programa

(71) Id. Ibid., p. 28.

(72) PATRÃO NEVES, M. do Céu. Alocação de recursos em saúde: consideraçōes éticas. Bioética, Brasilia, v. 7, n. 2, p. 163, 1999.

(73) ROSSI, F. op. cit., p. 194. 
de ação em medicamentos essenciais; compreendendo por tais aqueles que satisfazem às necessidades de cuidado de saúde da maioria da população e que devem conseqüentemente estar disponíveis em todo o momento, em quantidades adequadas e em apresentações apropriadas, a um preço que a comunidade possa pagar ${ }^{(74)}$. As listas de medicamentos essenciais são elaboradas pela OMS anualmente, considerando seu impacto para a saúde pública, a evidência de sua eficácia ou inocuidade e o preço acessível para as pessoas e a comunidade. Elas são confeccionadas com base em numerosos programas de saúde desenvolvidos com o objetivo de reduzir tanto a morbimortalidade nos países em desenvolvimento, quanto os gastos com medicamentos que comprometem parte importante de suas rendas. Em 2002 pela primeira vez a lista incorporou 12 anti-retrovirais para o tratamento da AIDS. Essa campanha teve desenvolvimento positivo, traduzido num aumento considerável da população com acesso a essas listas de medicamentos.

Garantir o acesso aos medicamentos essenciais é considerado hoje como uma das responsabilidades indelegáveis do Estado e constitui um tema incluído na agenda dos diferentes países e dos organismos internacionais. O numeral 17 das Metas das Naçōes Unidas para o Milênio estabelece especialmente a necessidade de "proporcionar o acesso aos medicamentos essenciais nos países em desenvolvimento".

Apesar de todas as ações desenvolvidas neste sentido, a OMS assinala que mesmo hoje um terço da população mundial continua sem um acesso regular a estes medicamentos. Considerando que nas populações pobres $60 \%$ das mortes são produzidas por infecções parasitárias, tuberculose e malária, todas para as quais o acesso oportuno aos medicamentos é geralmente decisivo para prolongar a vida e reduzir o. sofrimento, podemos perceber o que significa que um terço da população mundial careça ainda de acesso aos medicamentos essenciais. Na África, 320 milhões de pessoas somente têm acesso a menos de $50 \%$ da lista de medicamentos essenciais; o que a esta altura do século constitui um insulto verdadeiro à dignidade dos seres humanos, que nos deveria envergonhar.

A Dra. Gro Harlem Brundtland, ex-diretora da OMS, recordou que nunca o mundo teve tantas armas terapêuticas para as doenças que afligem a humanidade; porém, ao mesmo tempo existe uma necessidade vital de medicamentos e de vacinas novas. Isso é verdade para as doenças emergentes, mas também o é para a ameaça séria que representa a resistência crescente aos medicamentos usados contra doenças mortais comuns como a malária, a meningite e a pneumonia bacteriana(75). Apesar do trabalho elogiável da OMS no plano internacional, estamos longe de concretizar a proposta "saúde para todos no ano 2000". Os países mais pobres, quase esquecidos da mão

(74) WHO/DAP/98.9.

(75) BRUNDTLAND, G. H., en OMS: Globalización, acceso a los medicamentos (WHO/DAP/98.9). 
de Deus, dizimados pelas dívidas externas impossiveis de pagar, vítimas de práticas comerciais que afetam ostensivamente sua renda (subsídios, barreiras alfandegárias etc.) são aqueles que estão mais distantes de poder oferecer a seus habitantes a provisão universal de medicamento essencial.

O aumento do arsenal terapêutico não se traduziu em um aumento correlativo do acesso aos medicamentos, assim quem tem menos renda, ou simplesmente carece dela, não pode suportar o preço, e a contribuição estatal em muitos casos é insuficiente ou simplesmente inexistente. Tudo isso conduz à verificação de que o slogan "saúde para todos" está traduzido em muitos casos em "saúde para aqueles que contam com meios para o acesso". Esta lamentável comprovação deve servir para redobrar os esforços tendentes a eliminar as barreiras que impedem o acesso universal aos medicamentos, uma vez que assim poderia efetivar-se nos fatos o tantas vezes anunciado direito à saúde.

\section{O PAPEL DOS DIREITOS DE PROPRIEDADE INDUSTRIAL: DOHA E ALEM DE DOHA}

O obstáculo mais importante para o acesso aos medicamentos continua sendo o sistema da propriedade intelectual que, embora tenha experimentado alguma flexibilidade depois de Doha - tal como examinamos abaixo -, mantém sérias limitações traduzidas na imposição de preços elevados e na vantagem da estrutura monopolista dos mercados, ao lado das barreiras impostas à produção local nos países subdesenvolvidos. A tudo isso é necessário adicionar que muitos países em desenvolvimento viram-se forçados a aceitar níveis mais elevados de proteção da propriedade industrial do que aqueles estabelecidos nos acordos sobre os aspectos dos direitos de propriedade intelectual relacionados ao comércio (Acordo TRIPS), como aqueles que impuseram os Estados Unidos nos "acordos de livre comércio" à Cingapura, Jordânia, ao Chile, aos países centro-americanos, Colômbia, Peru, dentre outros. Esta nova "volta da porca" acentua ainda mais a situação de desvantagem em que estão estes países, já que afetará necessariamente o acesso aos medicamentos dos setores mais carentes.

Dissemos que o acesso aos medicamentos encontra uma cerca - às vezes difícil de saltar - no regime das patentes, visto que estas conferem monopólios temporais que influenciam não somente o preço, mas que paralelamente - retardam a introdução da concorrência. Isso levou numerosos países, em boa hora, a excluir os medicamentos da proteção patentária por considerá-los bens públicos; privilegiando desta forma a defesa da saúde de seus habitantes. Ao encerrar-se a Rodada do Uruguai do GATT (General Agreement on Tariffs and Trade, em português "Acordo Geral sobre Tarifas e Comércio"), um dos efeitos centrais que produziu foi a virtual globalização do sistema de patentes, embora na teoria se continue sustentando que se trata 
de direitos territoriais. Um capítulo central no Acordo TRIPS é o que estabeleceu padrões mínimos de proteção patentária, de observância obrigatória para os países que integram o sistema multilateral de comércio ali criado, sob pena de submeter-se a sanções comerciais em caso de infração.

Uma vez que fazer parte da Organização Mundial de Comércio (OMC) constitui uma necessidade imperiosa para os Estados, é possível sustentar que o que foi acordado no TRIPS de fato é de observância geral e obrigatória. Como compreende Remiche, a filosofia do Acordo consiste na adoção de medidas idênticas para o mundo inteiro e resulta de uma visão do mundo que o concebe como um grande mercado. Essa visão não resiste à análise frente à evidência revelada de um mundo diferenciado em que determinados interesses legítimos podem ser contraditórios ${ }^{(76)}$. Particularmente, no exemplo das patentes, estabeleceu-se que os Estados não poderiam fazer distinções fundadas em um ramo da tecnologia, com o que os países que até então excluíam os medicamentos da proteção patentária se viram constrangidos à necessidade de modificar suas legislações.

De conformidade com o acordo, durante todo o período de vigência das patentes - agora harmonizado em vinte anos - o titular goza do direito exclusivo de fabricar o produto, comercializá-lo, licenciá-lo, importá-lo e exportá-lo. Se a isso adicionarmos a circunstância já conhecida de que a indústria farmacêutica é monopolística, concentrada cada vez mais em um punhado das multinacionais que possuem a maioria das inovações nesse campo, temos como corolário natural que o acesso aos medicamentos protegidos por patentes - que constitui o segmento mais usado no tratamento das moléstias humanas - depende em grande medida das decisões industriais (fixação dos preços, privilégios, concessão de licenças, importação, exportação etc.), orientadas apenas pelo aumento do lucro.

O mercado farmacêutico não pode ser descrito pelo modelo do mercado clássico da concorrência perfeita, tendo em conta a existência de uma série de fatores, tais como: a assimetria na informação - os consumidores carecem, em geral, da informação necessária para avaliar a eficácia e a eficiência do produto e a tendência à inelasticidade da demanda ou dos preços (considerando, entre outras coisas, o caráter essencial do bem, os aumentos de preço não se refletem proporcionalmente no consumo) e a fidelidade às marcas e as barreiras de entrada de novos produtos (tecnológicas, de escala e metodológicas). Estas circunstâncias convergem para a redução das possibilidades de substituição do produto, seja pela falta de opções no mercado ou pela não identificação de tais opções por parte dos consumidores ${ }^{(77)}$. Isso

(76) Remiche, B. Les brévets farmaceutiques entre l'interêt privé et public: un equilibre imposible? Révue Internationale de Droit Économique, v. 1, p. 197, 2000.

(77) REIS, A. L. de Almeida dos; BERMÚDEZ, J. Aspectos económicos: mercados farmacéuticos y precio de medicamentos. In: BERMÚDEZ, J.; OLIVEIRA, M. A.; ESHER, A. op. cit., p. 139. 
mostra que, em um caso concreto, quem experimenta a necessidade de um determinado produto farmacêutico fica prisioneiro do mercado e é sabido que a indústria farmacêutica é uma das mais rentáveis, em função dos preços excessivos que impõem ${ }^{(78)}$. Quando se trata de ministrar drogas insubstituíveis para curar um mal ou prolongar uma vida podemos observar em toda sua dimensão a perversidade do sistema imperante.

Durante um momento os países menos desenvolvidos suportaram estoicamente os efeitos nefastos do sistema imposto pela OMC, sem encontrar maior eco na comunidade das nações, até que a pandemia de AIDS forçou os países mais afetados a usar recursos heróicos. A África do Sul rompeu o cerco injusto e inumano imposto pela ordem internacional e seu governo decidiu privilegiar a vida e a saúde de seus habitantes sobre os interesses do mercado, desconhecendo de fato o regime criado pelo Acordo ADPIC, o que a expôs a uma multiplicidade de demandas judiciais promovidas pelas multinacionais farmacêuticas. O que estava em jogo era a vida de mais de quatro milhões de infectados, a necessidade de evitar sofrimentos evitáveis e ao mesmo tempo levantar uma barreira à difusão do ma|(79). A reação geral que provocaram as demandas judiciais encabeçadas por diversas organizações não-governamentais mostrou ao mundo a iniqüidade e a falta de solidariedade das autoras, aquelas que - finalmente - tiveram que desistir de suas pretensões ante a repulsa generalizada.

Apesar dessa solução pontual, o problema gerado - a pretendida primazia dos interesses do mercado frente àqueles da saúde coletiva continou a existir. Em razão dele, o grupo africano no seio da OMC instou para que se considerasse no mais alto nível a relação entre a saúde pública e os acordos TRIPS. Já em 1996, a OMS havia examinado a relação entre a saúde pública e esses acordos. As resoluções adotadas em 2001 apontaram a necessidade de avaliar o impacto do Acordo TRIPS no acesso, na capacidade de produção local e no desenvolvimento de novos medicamentos. Mais tarde, em conseqüência do clima criado pelos ataques às torres gêmeas (World Trade Center, em Nova lorque), surgiu a denominada "crise do carbúnculo", gerada pelo medo da disseminação do antraz, por atos terroristas, o que colocou os Estados Unidos frente à eventualidade de ter que responder a uma demanda generalizada da única droga eficaz, cuja

(78) As diferenças de custo entre o princípio ativo e a especialidade medicinal que o contém resultam, muitas vezes, num abismo, o que foi demonstrado em numerosos estudos. Assim, foi verificado que de 12 medicamentos indicados para uma série de doenças, os preços nos Estados Unidos eram de 4 a 56 vezes superiores aos preços dos produtos equivalentes na Índia, país que ainda não protege os produtos farmacêuticos por patentes, utilizando o prazo de gratuidade estabelecido no Acordo TRIPS.

(79) Para se ter uma idéia aproximada dos ganhos exorbitantes da indústria farmacêutica, assinalamos que, entre jutho de 2000 e abril de 2002, o custo anual da combinação da terapia tripla anti-retroviral de marca, reduziu-se de mais de US $\$ 10$ mil ao ano por indivíduo para pouco mais de US $\$ 700$, para um grupo selecionado de consumidores. Nesse período o preço genérico mais baixo desta combinação havia descido para US\$290. 
patente pertence a uma multinacional, que não estava em condições de fornecê-la nem na quantidade, nem no tempo requerido.

O medo de um desenlace cruel - finalmente dissipado - provocou a reflexão sobre a necessidade de estabelecer um equilíbrio mais racional $e$ mais humano entre os direitos da propriedade industrial que usam as companhias e os interesses da saúde pública. Já não se tratava de uma reivindicação dos países da África Sub-Sahariana, mas de um problema que poderia ter atingido a maior potência econômica mundial. Sob esse clima celebrou-se o quarto período de sessões da Conferência Ministerial da OMC que examinou a pré-mencionada relação e que, como fruto de suas deliberações, produziu, em 14 de novembro de 2001, a denominada "Declaração de Doha", que implicou em um avanço substancial na luta dos países subdesenvolvidos para oferecer medicamentos acessíveis aos seus povos.

A declaração começa por marcar a gravidade dos problemas de saúde pública que afligem muitos países em desenvolvimento e aos menos avançados, especialmente pela epidemia de AIDS, tuberculose e malária e, ao mesmo tempo, reconhece que o acordo TRIPS não impede, nem deveria impedir, que os países adotem medidas para proteger a saúde pública, afirmando, nesse sentido, que tal acordo pode e deve ser interpretado e aplicado de maneira que suporte o direito dos membros da OMC de proteger a saúde pública e, em particular, de promover o acesso aos medicamentos para todos. Deve-se notar a relevância que recebe esta Declaração na qual, pela primeira vez, um órgão chave do sistema econômico internacional reconhece e privilegia os interesses da saúde pública, os quais coloca acima dos direitos de propriedade industrial.

Paralelamente, reconhece que o acordo TRIPS contém flexibilidades em sua aplicação, tais como: a) o dever dos membros de conceder licenças compulsórias e o de determinar as bases sobre as quais tais licenças serão concedidas; b) o direito de determinar o que constitui uma emergência nacional ou uma outra circunstância de extrema urgência, ficando entendido que as crises de saúde pública, incluídas as relacionadas à AIDS, tuberculose, malária e outras epidemias, podem representar uma emergência nacional ou outras circunstâncias de extrema urgência.

A declaração ministerial, que pode ser considerada como uma interpretação autorizada do Acordo, constituiu - sem dúvida - uma vitória dos países menos desenvolvidos ao pôr em primeiro plano a defesa dos interesses vinculados à saúde coletiva sobre os interesses particulares que podem derivar da observância dos direitos de propriedade industrial e dos acordos a eles vinculados. Como enfatiza Correa, a Declaração de Doha não pretende emendar o acordo sobre os ADPIC de nenhuma maneira substancial. A Declaração não inclui a totalidade das áreas em que existe a flexibilidade no Acordo sobre ADPIC, tais como as exceções ao direito das patentes, a proteção dos dados pessoais para o registro de produto farmacêutico; tão pouco 
faz referência à liberdade dos países para determinarem os padrões de patenteabilidade, de forma a impedir o desenvolvimento das estratégias de patenteamento dirigidas a cumprir ou a estender temporariamente a proteção conferida na área farmacêutica ${ }^{(80)}$.

Constitui uma fissura no sistema monolítico e perverso (que não foi desarticulado) e projeta uma fresta de luz nos caminhos da eqüidade e da solidariedade. Mais tarde um acordo complementar, de 3 de agosto de 2003, esclareceu alguns aspectos de sua execução o que permitiu a concessão de licenças compulsórias, com o fim de exportação, para atender às demandas dos países com pouca ou nenhuma capacidade de produção, suspendendo temporariamente as sanções contempladas no TRIPS.

Tal como se indicou, ao separar a saúde pública, e especialmente os produtos farmacêuticos, dos demais temas relacionados ao comércio, a Declaração de Doha reconhece que os medicamentos não são uma mercadoria qualquer, devendo ser diferenciados das demais mercadorias ao proteger a saúde pública(81). Não obstante, sua aplicação pode ser difícil em razão da complexidade e da lentidão dos procedimentos que se deve pôr em marcha para sua execução.

Seria aconselhável a reforma do TRIPS de modo que os países menos desenvolvidos fiquem à margem das obrigações ali estabelecidas com relação aos medicamentos. Na realidade dos fatos, sua participação no mercado mundial do medicamento é mínima e os problemas que devem confrontar para satisfazer as necessidades sanitárias de seus habitantes importam relevantes sacrifícios. Também os esforços devem ser orientados de modo a que os países menos desenvolvidos possam contar com tecnologia própria, sem necessidade de ter que recorrer a terceiros para importar o medicamento. O próprio texto do acordo original estabelecia que os países desenvolvidos oferecessem às companhias.e às instituições dos países menos avançados incentivos destinados a fomentar e propiciar a transferência de tecnologia, a fim de que estes pudessem estabelecer uma base tecnológica racional e viável. Lamentavelmente isto não se cumpriu e a transferência de tecnologia prometida ficou no papel.

Não é possível que o processo de globalização se traduza em exigências desmedidas para esses países, que não condizem com os benefícios que foram acordados para os industrializados. Aqui se impõe a observância de condutas solidárias por parte dos países desenvolvidos, que permitam aos países de terceiro mundo superar os problemas criados pela crise de saúde que os cerca. Como a OMS compreende, a fim de enfrentar os novos problemas de saúde de repercussão internacional, como o aparecimento da

(80) WHO/EDM/PAR/2002.3

(81) VELÁSQUEZ, Germán; CORREA, Carlos M.; BALASUBRAMANIAM, Thirkumarann. La OMS al frente de la lucha por el acceso a los medicamentos. In: BERMÚDEZ, J.; Oliveira, M. A.; ESHER, A. op. cit., p. 104. 
Síndrome Respiratória Aguda Grave (SRAS), o acesso aos medicamentos novos com possíveis efeitos terapêuticos, assim como às inovações e às descobertas em matéria de saúde, devem estar à disposição de todos sem discriminação.

A luta pelo acesso universal aos medicamentos em circunstâncias razoáveis, que não importem agravar a situação econômico-social dos países menos desenvolvidos nem infligir às populações carentes maiores sacrifícios e sofrimentos, constitui não somente uma decisão política, mas deve, paralelamente, comprometer os esforços dirigidos ao alcance de uma solidariedade maior entre nações e povos. Referindo-se a esse problema, Adela Cortina afirmou "que milhões de pessoas estão ameaçadas de morte nos países em desenvolvimento por AIDS, tuberculose ou malária; que existem as drogas adequadas para o tratamento e que o direito das patentes torna absolutamente impossível para essa gente ter acesso a eles; isso é um crime contra a humanidade. E exatamente contra a humanidade mais inerme e, por isso mesmo, mais vulnerável"(82).

Acredito que chegou o momento no qual a comunidade das nações deva "pegar o touro pelas unhas" e inverter os termos da equação. Em vez de tomar como ponto de partida a defesa dos direitos derivados da propriedade industrial em favor da indústria farmacêutica, torna-se imprescindível começar por analisar a situação em matéria sanitária de uma parte considerável dos países menos desenvolvidos, em especial da África e da América Latina, e empreender uma campanha solidária para tornar realidade o sonho de "medicamentos para todos". Se for necessário flexibilizar os Acordos de ADPIC, excluir os países pobres de seu regime, prolongar os prazos de gratuidade para o patenteamento das drogas, permitir importações paralelas, será imperativo recorrer a isso. Também os países desenvolvidos deveriam contribuir para a solução dos problemas que criam para os países subdesenvolvidos, relacionados à dificuldades econômicas para o acesso aos medicamentos, por meio de doações ou remissões da dívida.

A humanidade constitui uma grande família da qual ninguém pode fugir. Os problemas de um país ou de um continente cedo ou tarde impactarão os outros. A insensibilidade com a pandemia de AIDS, ou de tuberculose, ou malária, mais cedo ou mais tarde reverterá sobre os países desenvolvidos. Em vez de elaborar orçamentos incomensuráveis para a compra de armamentos destinados à destruição das populações de inimigos imaginários, devemos exigir-lhes uma quota de racionalidade e de solidariedade, já que nada nem ninguém poderá separar a comunidade das nações de um destino comum.

(82) Cortina, A. La arrogancia neoliberal. El País, Madrid, 16 set. 2003. 


\section{REFERENCIAS}

ABRAMOVICH, V.; Coutis, C. Hacia la exigibilidad de los derechos económicos, sociales y culturales. In: ABREGÚ, M.; COUTIS, C. Aplicación de los Tratados sobre derechos humanos por jueces locales. Buenos Aires: Editorial del Puerto, 1997.

BERLINGER, G. Ética de la salud. Buenos Aires: Lugar Edit., 1996.

BRUNDTLAND, G. H. In: OMS: Globalización, acceso a los medicamentos. (WHO/DAP/98.9).

CORTINA, A. La arrogancia neoliberal. El País, Madrid, 16.set.2003.

GARRAFA, V. Inclusão social no contexto político da bioética. Revista Brasileira de Bioética, v. 1, n. 2, 2005.

HOTTOIS, G. Bioética y derechos humanos. In: Escobar Triana, J. Y et al. (Orgs). Bioética y derechos humanos. Bogota: Ediciones del Bosque, 1998. (Colección Bios y Ethos).

INFORME de la Comisión sobre Derechos de Propiedad Intelectual del Reino Unido. In: Temas de Derecho Industrial y de la Competencia, n. 7. Buenos Aires: Ciudad Argentina, 2005.

MALDONADO, C. E. Necesidad de esencia y comunidad de problemas de la bioética y los derechos humanos. In: Escobar Triana, J. Y et al. (Orgs). Bioética y derechos humanos. Bogota: Ediciones del Bosque, 1998. (Colección Bios y Ethos).

PATRÃO NEVES, M. do Céu. Alocação de recursos em saúde: considerações éticas. Bioética, Brasilia, v. 7, n. 2, 1999.

PECUL, V. Los gobiernos deben responsabilizarse por tratar las enfermedades olvidadas. El País, Madrid, 18 abr. 2006.

PETER, F.; Evans, T. Dimensiones de la equidad en salud. In: AA. Desafío de la falta de equidad en la salud. Washington: OPS, 2000.

REIS, A. L. de Almeida dos; BERMÚDEZ, J. Aspectos económicos: mercados farmacéuticos y precio de medicamentos. In: BERMÚDEZ, J.; OLIVEIRA, M. A.; ESHER, A. Acceso a medicamentos: derecho fundamental: papel del Estado. Rio de Janeiro: Fiocruz, 2004.

REMICHE, B. Les brévets farmaceutiques entre l'interêt privé et public: un equilibre imposible? Révue Internationale de Droit Économique, v. 1, 2000.

ROSSI, F. Enfermedades de alto impacto social, enfermedades olvidadas, medicamentos de alto costo y ARV. In: BERMÚDEZ, J.; OLIVEIRA, M. A.; ESHER, A. Acceso a medicamentos: derecho fundamental: papel del Estado. Rio de Janeiro: Fiocruz, 2004. 
SCHRAMM, F. R. Bioética sin universalidad. Justificación de una bioética latinoamericana y caribeña de protección. In: GARRAFA, V.; KOTTOW, M.; SAADA, A. (Coords.). Estatuto epistemológico de la bioética. México: UNAM, 2005.

SEÚBE HERNÁNDEZ, X. El Derecho al acceso a los medicamentos esenciales y el comercio internacional de productos farmacéuticos. 2004. (Tesis) - Universidad Pompeu Fabra, Barcelona, 2004. Inédito.

SILVA, C. dos Santos; ZEPEDA BERMÚDEZ, J. Medicamentos esepcionais ou de alto custo no Brasil. In: BERMÚDEZ, J.; OLIVEIRA, M. A.; ESHER, A. Acceso a medicamentos: derecho fundamental: papel del Estado. Rio de Janeiro: Fiocruz, 2004.

TAPAJÓS, A. M. Patentes e acesso a medicamentos: estudio bioético de la Declaração de Doha. 2005. (Tesis). Brasília 2005. Inédito.

VELÁSQUEZ, E. Médicaments essencials et mondialisation. Revue International de Droit Économique, v. 1, 2000.

VELÁSQUEZ, Germán. El papel del Estado en el financiamiento de los medicamentos. In: BERMÚDEZ, J.; OLIVEIRA, M. A.; ESHER, A. Acceso a medicamentos: derecho fundamental: papel del Estado. Rio de Janeiro: Fiocruz, 2004.

VELÁSQUEZ, Germán; CORREA, Carlos M.; BALASUBRAMANIAM, Thirkumarann. La OMS al frente de la lucha por el acceso a los medicamentos. In: BERMÚDEZ, J.; Oliveira, M. A.; ESHER, A. Acceso a medicamentos: derecho fundamental: papel del Estado. Rio de Janeiro: Fiocruz, 2004.

ZATTI, R. Verso un diritto per la bioética. In: MAZZONI, C. M. (a cura di). Una norma giuridica per la bioética. Bologna: II Mulino, 1988. 